\title{
Production and comprehension of intersentential pronominal reference in early child Bulgarian - an experimental study
}

\author{
Milena Kuehnast \\ Centre for General Linguistics, Typology and Universals Research (ZAS) \\ Berlin, Germany
}

The paper presents results from a combined production and comprehension study addressing some of the factors which guide the establishment of intersentential pronominal reference in child and adult Bulgarian. We investigate the time course and different stages in the acquisition of null, personal and demonstrative pronouns and their specific anaphoric functions. We target possible age-induced changes in the salience hierarchy of referent features such as animacy and grammatical role. Following the general consent in the field of anaphora research, we assume a division of labour between different pronominal forms with respect to the salience of their referents. Based on the data of Bulgarian preschool children we investigate the validity of this form-function relation, its language-specific shape and its developmentally induced variation. The results reveal an initial prominence of animate referents which later on develops into preference for animate subjects. Although the investigated 3 to 5 year old Bulgarian children do not stick to the adult anaphora resolution strategy, they comply with the principle of the reversed mapping within the range of tested pronouns and react according to their salience criteria which promote animate subjects as the most prominent coreference candidates.

\section{Introduction}

In every communicative situation a speaker needs to choose such referring expressions that the addressee could reasonably establish a co-reference relation to the entity meant by the speaker. The success of such interactive communication processes depends on the evaluation of the referents' accessibility status by the

This study is part of a cross-linguistic investigation conducted together with D. Bittner and N. Gagarina and I. Gülzow. I am grateful to N. Tchenkova for transcribing and coding the data. I'm indebted to E. Andonova for her support in the statistic analysis. 
communication participants and on their ability to encode the accessibility status by means of appropriate referring expressions.

Theories dealing with the mapping between the accessibility status of the referent and the type of referring means (Ariel 2001 \& 2004; Givón 1983; Gundel, Hedberg \& Zacharski 1993; Levinson 2000, inter alia) have established a reversed correlation between the complexity of referring expressions and the activation status of a referent in the working memory. Referents which are in the focus of attention need the simplest referring expression and vice versa. ${ }^{1}$ Such a reversed mapping presupposes two ordered sets. The first set reflects a ranking of referents according to their accessibility score. The second set concerns the number and the ordering of available referring expressions according their complexity.

From a developmental perspective, the time course and possible stages in the acquisition of intersentential pronominal reference have to be investigated in order to provide language specific and cross-linguistically valid evidence for the following questions: Do children rely on a unique salience hierarchy of referent features as diverse as animacy, agency, syntactic role, linear distance or discourse status and are there age induced changes in the feature ranking? When and in which contexts do children use structural contrasts between pronominal classes to uniquely identify ambiguous referents? Are there general developmental patterns and do they diverge or converge in a cross-linguistic comparison?

While it is possible to assume the universal validity of the reversed mapping between the salience rank of referents and the complexity of referring expressions, both sets taken separately are subject to language dependent variation. In order to set up the conditions of successful co-reference establishment in a given language, both sets are to be considered in more detail.

\subsection{The set of referring expressions in Bulgarian}

Bulgarian is a South-Slavic language with a relatively free word order, but SVO is perceived as the basic variety. As a member of the Balkan linguistic union, Bulgarian exhibits some nominal properties which set it apart from the other Slavic languages. Bulgarian is an analytic language and has no nominal case system. The only preserved case differentiation amounts to the accusative and dative forms of the short personal pronouns. Bulgarian nouns are organised in a 3 -gender system. Nominal definiteness is expressed by means of gender/number specific enclitic definite articles attached to the first member of the nominal

1 See Kaiser (2005) for a different approach to anaphora resolution and argumentation against a unified notion of salience. 
phrase. Additionally, nominal definiteness may also be marked by a demonstrative pronoun heading the nominal group like in all other Slavic languages.

A special feature of Bulgarian is its double pronominal system: the classes of the personal, the reflexive and the possessive pronouns exhibit a system of full (long) and enclitic (short) pronominal forms. The use of the short pronoun together with its full form or with a noun is a phenomenon known in the literature as 'clitic doubling' and is subject to pragmatic restrictions such as topic marking. The pronouns of the $3^{\text {rd }}$ person singular exhibit gender distinctive forms in nominative and the oblique cases.

Bulgarian speakers may alternate between an overt and a covert realisation of the subject position. Morphologically distinct agreement markers on the verb assure the person/number identification. Bulgarian is a typical subject-drop (or pro-drop) language (see Bojadzhiev et al. 1999:596f. for the application of defining typological criteria to Bulgarian). Personal pronouns for first and second person singular and plural are obligatorily left out if not emphatically stressed.

Sentences with a non-overt realisation of a $3^{\text {rd }}$ person subject may be formally divided with respect to the grammatical person and number of the pronoun (see definitions and functions in Andreicin 1978). Subjectless sentences with $3^{\text {rd }}$ person plural predicates function similarly to passive sentences. They highlight the action without naming the performer. Such constructions are called unspecified personal sentences. The dropped subject is understood as referring to a human performer. The distinction between singular and plural is neutralised, in the sense that the construction is felicitous even if a single person carries out the action (Rå Hauge 1999:134). The main characteristic of the unspecified personal constructions is the requirement that the dropped subject has to be a person.

Compared to the clear interpretation of the unspecified personal constructions, the non-overt realisation of the subject in clauses with $3^{\text {rd }}$ person singular predicates is a phenomenon whose felicity conditions still lack a precise description. There is a general consent that the subject of a clause may be dropped if its referent is apparent to the participants of a given communicative situation. This general rule surfaces differently in spoken and written language. While in a spoken discourse a highly accessible referent may be referred to by a null pronoun without a preceding explicit introduction, in written discourse the referent has to be introduced explicitly. In written discourse a null pronoun needs an antecedent, in spoken discourse not necessarily. Consider a situation in which a father sees the mother coming out of their son's room. The subject drop in both dialog utterances (1a) and (1b) is not only grammatical and acceptable but actually the preferred option. 
(1) a. Spi li?

sleep 3 SG PRES IMPF question particle

Is (he) sleeping?

b. Da, naj-nakraja zaspa.

Yes last end sleep 3 SG AOR PF

Yes, in the end (he) fell asleep.

The picture becomes more complicated if there is more than one available referent. In such cases morphological markers play a disambiguating role. Apart from the general consent that the overt subject expression may be left out if its referent is accessible from the context (by virtue of its salience or semantic inference), Bulgarian grammarians (Nicolova 1986:43; Ilieva 1985:31) concede that the establishment of co-reference relations by means of non-overt $3^{\text {rd }}$ person singular pronouns still awaits a profound analysis. The use of overt $3^{\text {rd }}$ person personal pronouns in contexts with several probable antecedents seems problematic, too. The gender distinction expressed in the overt $3^{\text {rd }}$ singular personal pronouns, which is the only difference between the overt and non-overt pronominal realisations, ${ }^{2}$ is an important but often not a sufficient disambiguation cue. In a context with a high ambiguity potential, substitution of a subject-drop by an overt personal pronoun often cannot resolve the referential vagueness, because of the tiny functional difference.

The distribution of demonstrative pronouns in Bulgarian deviates considerably from the function of demonstratives in the anaphoric systems of the other Slavic languages. Definite demonstrative pronouns are divided into the classes of proximal tozi/toja 'this' and distal pronouns onzi/onja 'that'. More important than the proximal / distal difference is the functional differentiation between the neutral demonstrative form tova, on the one hand, and the feminine and masculine forms, on the other. The neutral proximal pronoun tova 'this' is the basic deictic marker similar to a pointing gesture (and often accompanied by such). It is the standard means used for the selection and identification of a particular referent in choice situations.

Utterances containing bare masculine or feminine demonstratives are very infrequent and are treated by the speakers as not really well-formed. Ivančev (1978:225) argues that utterances like (2a) if accepted are actually understood as elliptic nominal phrases as in (2b). A personal pronoun seems to be the most felicitous expression (2c).

2 The formal difference between overt and null subjects with respect to the expression of gender is obviated in cases of complex predicates containing past participles which exhibit gender agreement. 
(2) a. ? Tazi e pevica.

this proximal DEM 3SG FEM be 3SG PRES IMPF singer FEM SG INDEF

This is a singer.

b. Tazi zhena e pevica.

this proximal DEM 3SG FEM Woman FEM SG be 3SG PRES IMPF singer FEM SG INDEF

This woman is a singer.

c. Tja e pevica.

She 3 SSG FEM be 3 SG PRES IMPF singer $_{\text {FEM SG INDEF }}$

She is a singer.

In Bulgarian, anaphoric uses of bare demonstratives are considered oldfashioned and bad style. (Ivančev 1978:185f.; Rå Hauge 1999:53). Opposite to Czech and to some extent to Russian, Bulgarian does not employ bare demonstrative pronouns to signal that an antecedent from the focus part of the preceding sentence has become the topic in the current sentence. Bulgarian demonstratives are able to function properly as anaphoric devices only in complex nominal phrases in which they appear as specificity markers. In such cases the demonstrative pronoun as a part of a synonymous nominal phrase (3c) signals a topic shift and enters into an opposition to the definite article (compare also Ginina 1980). The demonstrative nominal phrase contrasts also with the personal pronoun which tends to preserve the established topic referent (3b). Consider the possible continuations of a discourse segment introduced as in (3a).

(3) a. Dirigentăt ${ }_{\mathrm{i}}$ srestna tenora $\mathrm{k}_{\mathrm{k}}$.

The conductor met the tenor.

b. Toj $\mathrm{i} / \mathrm{k}_{\mathrm{k}}$ ne beshe dovolen ot izpălnenieto.

He was not happy with the performance

c. Tozi ambizosen pevez ${ }_{\mathrm{k}}$ ne beshe dovolen ot izpălnenieto.

This ambitious singer was not happy with the performance

While the personal pronoun in (3b) tends to be resolved to the conductor, the very explicit demonstrative phrase shifts attention to the singer (3c).

The rank of demonstrative pronouns within the means establishing discourse co-reference in Bulgarian is perhaps best understood through its cataphoric function. Prototypically, the bare demonstrative pronoun appears as head of a defining relative clause (4). This complex syntactic construction illustrates the fact that demonstratives appear in expressions promoting referents which are not in the focus of attention and actually still have to be identified more pre- 
cisely (cf. Charalosova 1995 for an extended discussion of the deictic and anaphoric functions of Bulgarian demonstrative phrases).

Tozi, kojto e vzel knigite, trajva da gi varne.

This 3 SSG MASC who take 3 SSG PERF PF must to bring 3 3SG PRES PF them back The one who has taken the books must bring them back.

Figure 1 presents a (non-exhaustive) list of referring expressions in Bulgarian which are ordered relatively according to their increasing formal complexity. Obviously, in the set of anaphoric referring expressions the pronouns appear to be the minimally complex forms. The difference between null pronouns and personal pronouns in subject position amounts to a morphological gender expression in the $3^{\text {rd }}$ person singular. There is more pronounced increase of formal complexity with respect to the oblique cases of the personal pronouns which is based on the double system comprising full/short forms. The definite demonstrative pronouns have left their position in the row of anaphoric pronouns and have acquired a new one in the row of nominal phrases.

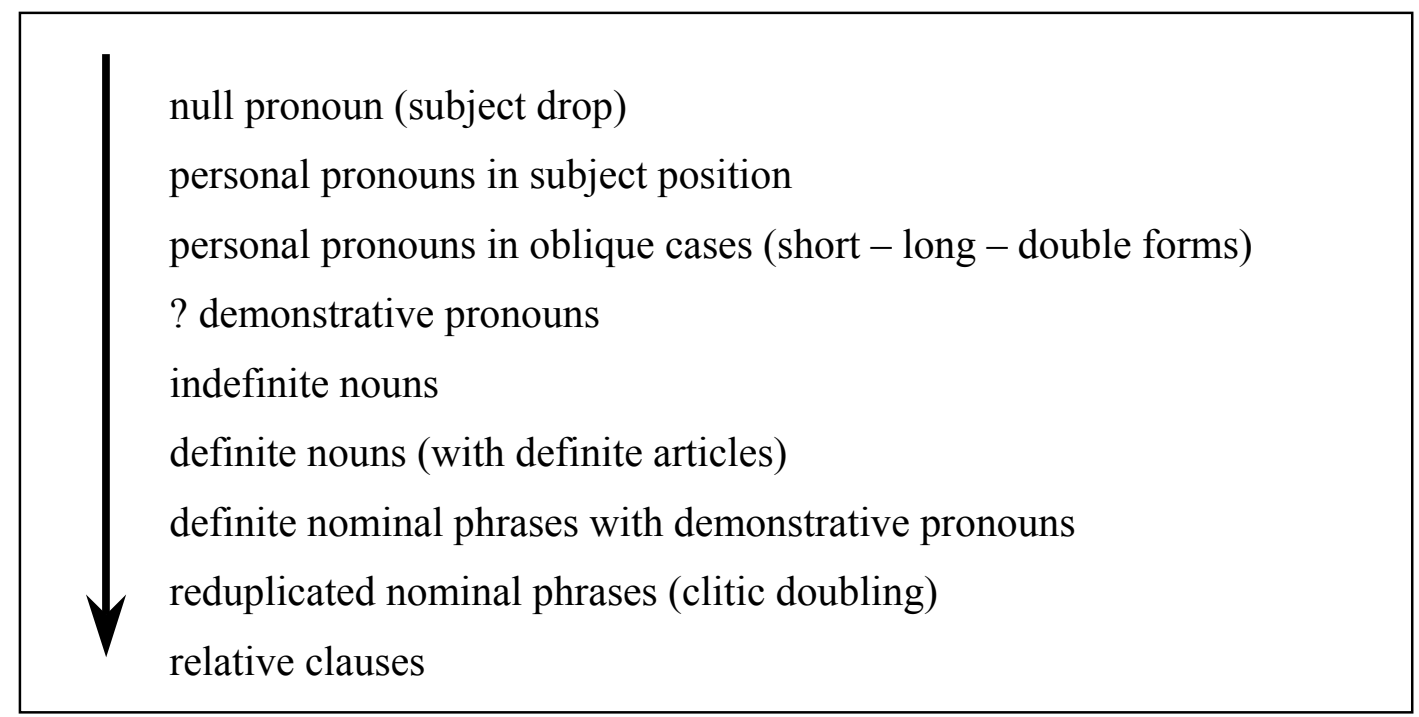

Figure 1: Types of anaphoric expressions

The complexity-based opposition between personal and demonstrative pronouns as anaphoric pronouns known from other Slavic (e.g. Czech) or Germanic languages (e.g. German) appears in Bulgarian on the level of definite noun phrases as a functional opposition between the definite article and the demonstrative pronoun in their functions as determiners. 


\subsection{The concept of salience and salience determining factors}

The literature on discourse organisation in Bulgarian and in particular on the establishment of intersentential co-reference relations reveals a clear influence of the Prague linguistics school and its theory of the functional sentence perspective. As far as the function and distribution of different pronominal types are treated in discourse context, this happens according to their appearance in the theme (topic) or in the rheme (focus) part of the sentence. Theme and rheme are understood as pieces of information structure differentiated by their degree of communicative dynamism (cf. Sgall, Hajicova \& Panevova 1986). Grammatical role and word order are some of the basic notions determining the dynamism degree. Subject status and preverbal position are associated with the theme, the part with the lowest dynamism status. The subject is the pivot of the predication and therefore the most static piece of information. The subject referent is thus easily accessible, representing an entity of the knowledge shared by the communicative partners. According to Hajicova, Partee \& Sgall (1993) this property of topic subjects makes them highly accessible for pronominalisation.

To start with the use of null pronoun in Bulgarian, let us consider the felicity condition of subject drop in the formulation of Maslov (1981:356) "The obligatory semantic-syntactic condition for implicitness of the subject is its identity with the theme." (translation M.K.). An implicit prerequisite for the application of the definition is the need to determine which one of the antecedents is best candidate to become the theme of the anaphoric sentence. Only then the antecedent will be accessible for a non-overt reference. Some Bulgarian scholars (e.g. Ivančev 1978) favour "the march of ideas", stating that rhematic referents are in the focus of attention, and therefore they are the preferred candidates to become the topic in subsequent sentences.

In a comparison between Czech and Bulgarian use of pronominal reference Uhliřova (1990:281) also points out that in Bulgarian, anaphoric subject drop is often used to take up a referent associated with the rheme (non-subject antecedent) of the preceding sentence. Further she notes that the use of personal pronoun is always possible, while subject drop is correlated with an informationally non-actualised referent (theme continuation). In this sense Ivančev (1978:175) says that subjects expressed by personal and null pronouns represent transition elements in the information load of an utterance. In a further development of this idea, Leafgren (2001) shows that in Bulgarian, personal pronouns and subject-drop keep track to one referent entity. The use of these minimal pronominal types marks the establishment of a discourse theme.

Whether the antecedent subject or object will be pronominalised in the subsequent utterance and by which pronoun type depends partly also on the animacy of the referent. Traditionally, animacy is not treated as a morphologi- 
cally expressed nominal category, ${ }^{3}$ mainly because Bulgarian has lost its case system which in the remaining Slavic languages helps to mark animacy differences. Nevertheless, the semantic notion plays a significant role as discourserelevant factor. It is utilised as an important disambiguation factor in models of natural language processing. In her algorithm of pronominal resolution, Ilieva (1985) applies animacy as the primary disambiguation criterion and only afterwards morphological filters for gender and number. Animacy is assigned a comparable rank also in advanced automatic models of anaphora resolution as a part of the semantic module (see Mitkov 1994).

Recalling the brief discussion of sentence types with null-subjects in section 1.1, animacy and especially humanness turn out as features which make a referent even more accessible to null anaphors in Bulgarian. These types of subject-drop constructions provide a peace of evidence supporting Comrie's generalisation "...the most natural kind of transitive construction is one where the A is high in animacy and definiteness, and the $P$ is lower in animacy and definiteness; and any deviation from this pattern leads to a more marked construction." (Comrie 1989:128).

\section{Empirical investigation}

In order to gather more empirical facts about the assumed relationship between the activation status of the referent and its linguistic encoding, we designed an experiment which was conducted with Bulgarian adults and children. ${ }^{4}$ The activation status of a referent depends on a quite inhomogeneous array of factors functioning on the sentence level and on the discourse level.

In the present study we investigate the factors animacy and grammatical role in terms of their relative weight for the activation status of an available referent. The chosen experimental method guarantees that other important factors such as differences in giveness (cf. Gundel, Hedberg, and Zacharski 1993) were controlled by the perceptual availability of both referents. On the level of linguistic expression, the equality of giveness values was upheld by using only definite nouns for the constitution of the context.

With respect to the types of referring expressions, only pronominal anaphors in subject position were tested. We selected three types of pronouns which differ from each other by the degree of formal complexity, the distance between them in the set of anaphoric expression and their acceptability as anaphoric means both in terms of grammatical well-formedness and pragmatic appropriateness.

3 See literature overview and extended discussion on animacy as nominal category in Bulgarian in (Kostadinova 1995).

4 Parallel experimental investigations were conducted with German and Russian children. See extended discussions by D. Bittner and N. Gagarina in the present volume. 
Assuming a universal application of the reversed mapping between anaphoric complexity and the accessibility of referents, we expect that Bulgarian adults comply with this principle within the functional distribution of anaphoric expressions in Bulgarian, and in particular within the pronominal system. Looking at the co-reference understanding of the adult speakers, we seek empirical evidence supporting or rejecting the hypothesis that the investigated salience properties are hierarchically ordered in Bulgarian.

The investigation of child language aims at determining whether formal complexity (understood as length of the sound string) is the criterion children choose as a starting point in the acquisition of co-reference establishment by means of anaphoric pronouns. The pro-drop property of Bulgarian allows an insight into the development of a referential technique in which the referring expression does not exhibit a physical form, and into the mechanism promoting its differentiation from techniques working with overt anaphoric means. Given the high frequency of subject drop in Bulgarian, we investigate how young children assign an interpretation to the null pronoun and which factors they initially rely on for co-reference establishment.

A basic aim of the study is to find out whether children start with the same interpretation of null pronouns as adults. If they do so, what is the most important referent feature which guides their interpretation? In case the subject-drop interpretations of young children and of adults deviate, two issues are of interest. Is the interpretation difference based on a different ranking of the investigated salience cues? At which age does this difference disappear and what developmental pattern leads to the adult way of understanding null anaphors?

As a next step, the study aims at possible differences between the interpretation of null, personal and demonstrative pronouns based on their different perceptual salience (sound length). The analysis of the production sample of the three pronouns in terms of quantity and distribution will provide additional information about the assumed influence of the investigated referential properties - animacy and syntactic role - on the use of pronominal anaphors. Taken together all these information sources allow inferences concerning the primary research question: Do children acquiring Bulgarian as a first language comply with the reversed mapping principle when they produce and comprehend anaphoric pronouns?

\subsection{Experimental method}

We conducted a combined production and comprehension experiment comparing the performance of children and adult groups. The intention behind the experimental design is to find out how Bulgarian children of different age groups 
interpret salience cues like animacy and syntactic role when producing and resolving pronominal anaphora of varying complexity in ambiguous situations.

\subsubsection{Subjects}

A total of 151 monolingual Bulgarian children participated in the experiment. As indicated in Table 1, the children were divided in 5 homogeneous age groups in age brackets set 6 months apart.

The children were tested in a separate room in their kindergarten. Additionally, 20 adult Bulgarians (16 to 54 years old, mean age 34) were tested as a control group. The experiment was conducted in Vidin, and therefore all subjects speak the North-Western variety of Bulgarian.

Table 1: Age groups

\begin{tabular}{|l|l|l|l|}
\hline Group & Mean age & Age bracket & Number \\
\hline 1 & $3 ; 0$ & $2 ; 10-3 ; 03$ & 30 \\
\hline 2 & $3 ; 6$ & $3 ; 04-3 ; 09$ & 30 \\
\hline 3 & $4 ; 0$ & $3 ; 10-4,03$ & 32 \\
\hline 4 & $4 ; 6$ & $4 ; 04-4,09$ & 28 \\
\hline 5 & $5 ; 0$ & $4,10-5,03$ & 31 \\
\hline
\end{tabular}

\subsubsection{Materials and design}

We conducted a combined production and comprehension experiment in the form of a playing situation. The subjects were presented with short stories (mean length 5 clauses) about two protagonists, acted out with puppets by the experimenter, who tells the story. A second experimenter played a distracted penguin using a hand puppet. In the production part of the experiment, the penguin named Toto asked the children to repeat an anaphoric utterance. In the comprehension part, the penguin prompted the children to resolve the pronoun by asking them to choose one of the referents.

The stories represent 4 constellations of referent properties lined up according to the factors ANIMACY ( \pm animate) and SYNTACTIC ROLE (subject/object). We constructed 4 antecedent sentence types (see Table 2) and combined each of them with 3 different anaphoric utterances - one with subject drop, one containing a personal pronoun and one with containing a demonstrative pronoun. 
Table 2: Combination of referent features in the antecedent sentences

\begin{tabular}{|c|c|c|}
\hline Sentence & Subject \& object animacy & \multicolumn{1}{c|}{ Example } \\
\hline A & animate SUB \& animate OBJ & The lion is biting the tiger. \\
\hline B & inanimate SUB \& animate OBJ & The ball is touching the bear. \\
\hline C & inanimate SUB \& inanimate OBJ & The bus is pushing the tractor. \\
\hline D & animate SUB \& inanimate OBJ & The elephant is driving the tractor. \\
\hline
\end{tabular}

In order to control gender cues, the nominal antecedents were always of the same gender, either masculine or feminine. In Bulgarian, ball and bear are feminine nouns. For subsequent reference by means of a $3^{\text {rd }}$ person singular personal pronoun, the feminine form tja - "she" has to be used. We tested the disambiguation power of 3 pronominal types with increasing complexity: null pronouns (subject-drop), personal pronouns and proximal demonstrative pronouns.

We prepared 2 sets of stimuli for the resulting 12 conditions. The children were randomly assigned to one of the two stimuli sets. The stimuli were randomised by means of the Latin square. The experiment was conducted in two sessions of 6 stimuli each, with a break between them in which the children did a story telling task.

\subsubsection{Procedure}

The children were tested in a quiet room in the kindergarten. The child and the two experimenters sat together at a table. The first experimenter introduced to the child the second experimenter as Toto the penguin, who came to Bulgaria for a holiday. Then she explained that she is going to show some toys and to tell stories about them. The children were told that Toto is a little distracted and does not understand Bulgarian properly because he comes from the South Pole. The children were asked to listen carefully to the stories and to help Toto if he misses the point.

In each stimulus unit, the penguin asked the child to repeat the target utterance which was the last one in the story. Usually the child repeated the anaphoric sentence more or less correctly. The anaphoric sentence makes a statement about a visual property which is true for both referents. In this situation of ambiguous reference, the penguin asked the child a clarification question in order to find out which referent is meant by the child. Usually the child named the referent and pointed at it. Some children responded only by pointing. A stimulus example and the course of the procedure are illustrated in Figure 2. Each subject received a training session. The child received only positive feedback, independent of repetition accuracy and referent choice. The children were videotaped in such a way that there faces were not visible. 
Exp. 1:

Look! This is a ball and this is a bear.

(Both toys are white.)

The ball is falling on the table.

The ball is springing on the table.

Antecedent clause: $\quad$ Now the ball is touching the bear.

Anaphoric clause:

It / this / Ø is white.

Exp. 2 (Toto):

I didn't understand. Repeat this for me, please.

Child: (production)

It is white.

Exp. 2 (Toto):

Who is white?

Figure 2: Experimental procedure

\subsection{Transcription and coding}

The videotapes were transcribed by a native speaker. A $10 \%$ sample of randomly chosen transcripts was checked for accuracy by a second person. No deviations were found.

The answers the children gave in the production part of the experiment were coded in the following 6 categories: null pronoun (NULL), personal pronoun (PP), demonstrative pronoun (DEM), noun (N), ellipsis (E) and no answer. Personal and demonstrative pronouns were coded respectively, independent from their status as (in)correct repetition with respect to the given pronoun type. The responses were assigned to the noun category when children used a bare noun, a definite noun (with a post-posed definite article), a definite nominal phrase consisting of a noun and a demonstrative pronoun, or a proper name. If a child responded with an utterance of the type "This bear is white", the answer was assigned to the noun category, although the child also produced a demonstrative pronoun. Cases in which the children produced only the adjective "White." without the copula verb were coded separately as ellipsis. As null pronouns were coded only the cases in which children produced verbs (full verbs/copula) whose agreement markers signal the presence of a null pronoun. Note that in Bulgarian utterances with subject drop like "Is white" or more literary "Ø white is." are completely well-formed even in copula constructions. Cases in which children remained silent were coded as no response.

For the comprehension part of the test we coded the responses to the "Who?" question in the following way: The syntactic role of the chosen referent was coded as subject or object according to the syntactic role of the antecedent in the preceding sentence. The same word order (SVO) was preserved in all antecedent sentences - the subject was always the first noun and the object the second one. All animal puppets were coded as animate, the remaining toys as inanimate. No dolls resembling humans were used. 
Some children did not resolve the ambiguity by stating that both referents exhibit the property in question. Such responses were coded as unclear and were not taken into consideration later on. Also as unclear were coded responses in which the child named one referent but pointed to the other, or used a different ambiguous noun such as "the vehicle" in a situation containing a bus and a tractor as referents. The last two response types appeared very seldom, under $1 \%$. As no response were coded the cases in which the child did not react to the comprehension question either by naming or pointing.

\section{Production data}

In the experiment a total number of 151 children participated. For the evaluation of the production part 11 children had to be excluded, because they did not repeat anything. 9 of the children were in age group 1 (mean age 3;0) and 2 children were in the second group (mean age 3;6). The remaining 140 children achieved a high task compliance rate, producing pronouns in $92 \%$ of the time. Figure 3 presents the distribution of valid answer types. A full compliance with the repetition task would amount to an average distribution of $33,33 \%$ for each given pronominal type and no elliptic or nominal responses.

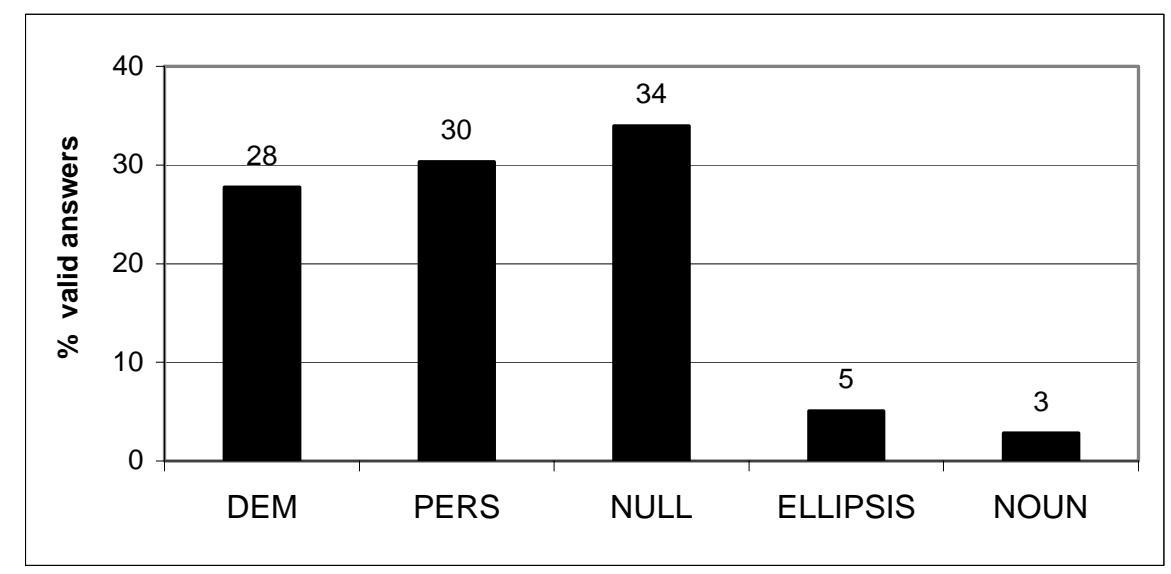

Figure 3: Distribution of valid response types

The slight preference for null pronouns - sentences with subject drop - decreases with age (compare Figure 3 and Figure 4). The same is true for the elliptical answers, in which the children repeated only the adjective and left out the copula. The use of nouns shows a slight increase with age, but is hampered by the better task compliance of the older children. 


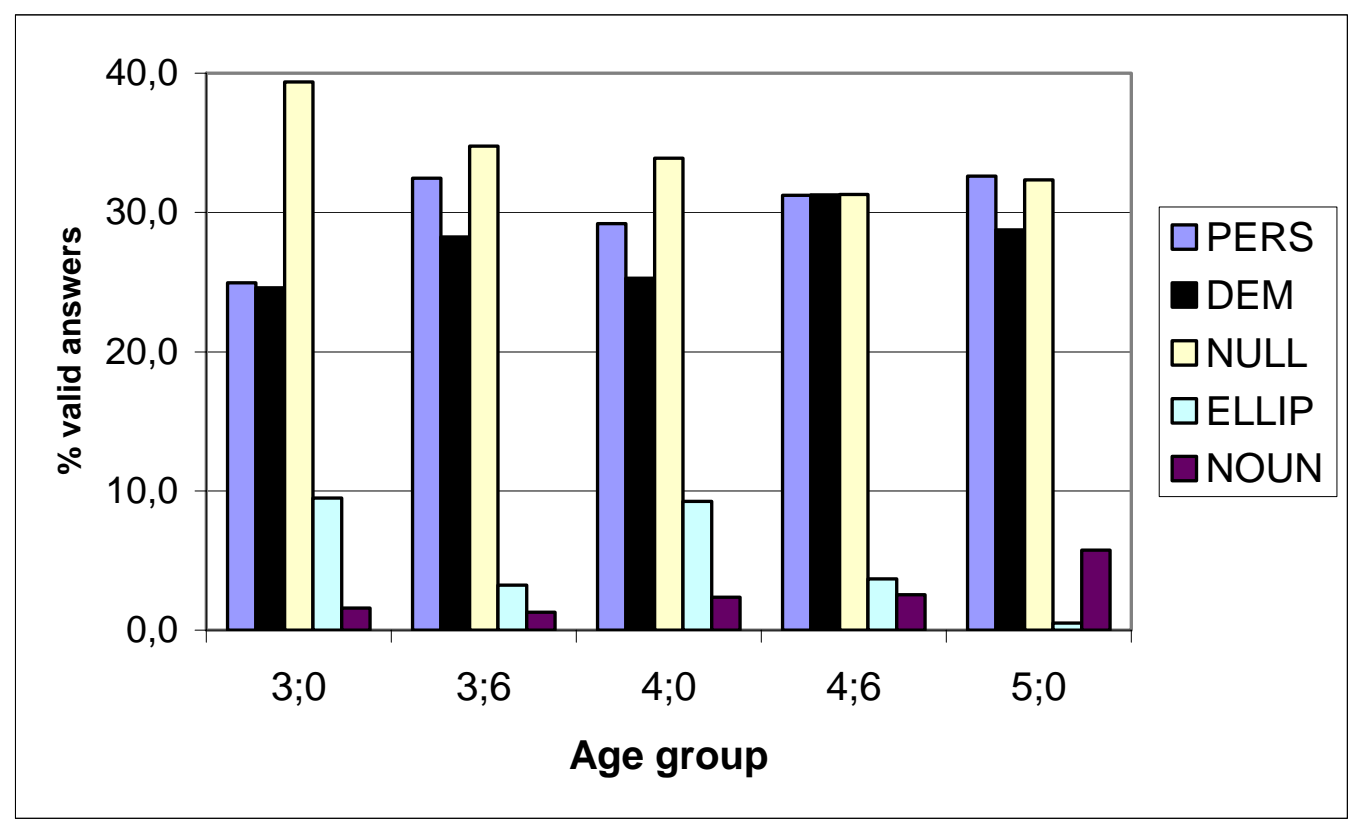

Figure 4: Repetition pattern per age group

The pattern of production errors excludes substitution of a null pronoun by a demonstrative pronoun. The most frequent deviation from the given pronoun is substitution of demonstrative and personal pronouns by subject drop. This production pattern is most characteristic for the youngest tested children and becomes levelled by the increase of personal pronouns already at the next age bracket (mean age 3;6). Apparently, younger children tend to produce elliptical answers, repeating only the adjective. This behaviour disappears with age. Apart from formal considerations (presence/absence of a predicate bearing agreement markers), the differentiation between utterances with subject drop and elliptic utterances is discussed from a comprehension point of view in section 4.2.2.

The age development of pronominal production was traced by a one-way ANOVA with the factor AGE GROUP on the proportion of produced pronouns per sentence type. We found a significant developmental change for each of the tested pronouns in sentence A (e.g. for the rate of personal pronouns $\left.\mathrm{F}_{(4 ; 139)}=2,614 \mathrm{p}>.044\right)$. Tuckey's post-hock comparison between group 1 and group $4(p<.068)$ reveals an increase of personal pronouns which reaches significance in group $5(\mathrm{p}<.033)$. The high rate of null pronouns produced by the youngest group decreases significantly already at the next age bracket $(\mathrm{p}<.045)$. The age effect on the production rate of demonstratives $\left(F_{(4 ; 139)}=2,386 \mathrm{p}>.054\right)$ reflects an overall increase of produced demonstratives. Tuckey-HSD reveals no significant differences between the single age groups.

A significant age induced change was also found for the production rates of null pronouns in sentence $\mathrm{D}\left(\mathrm{F}_{(4 ; 139)}=4.601 \mathrm{p}>.002\right)$. Similar to the developmental pattern of subject-drop in sentence $A$, we see a decrease of null pronouns 
with age. However, the significant change $(p<.001)$ appears later, namely between the production score of group 1 (3-year-olds) compared to group 3 (4years-olds). This difference remains valid also between group 1 and all remaining older children in the groups 4 and 5. All other comparisons did not reach significance. In the following, we present a descriptive analysis of the production behaviour according to the 4 sentence types per age group.

Group 1 (mean age of 3;0) produces a significantly higher number of utterances with subject drop than with personal pronouns (Wilcoxon ${ }_{(2,21)} \mathrm{z}=-2.54$; $\mathrm{p}<.011$ ), or with demonstrative pronouns (Wilcoxon ${ }_{(2,21)} \mathrm{z}=-2.414 ; \mathrm{p}<.016$ ) in sentence A, and similarly in conditions $\mathrm{C}$ and D (see Figure 5).

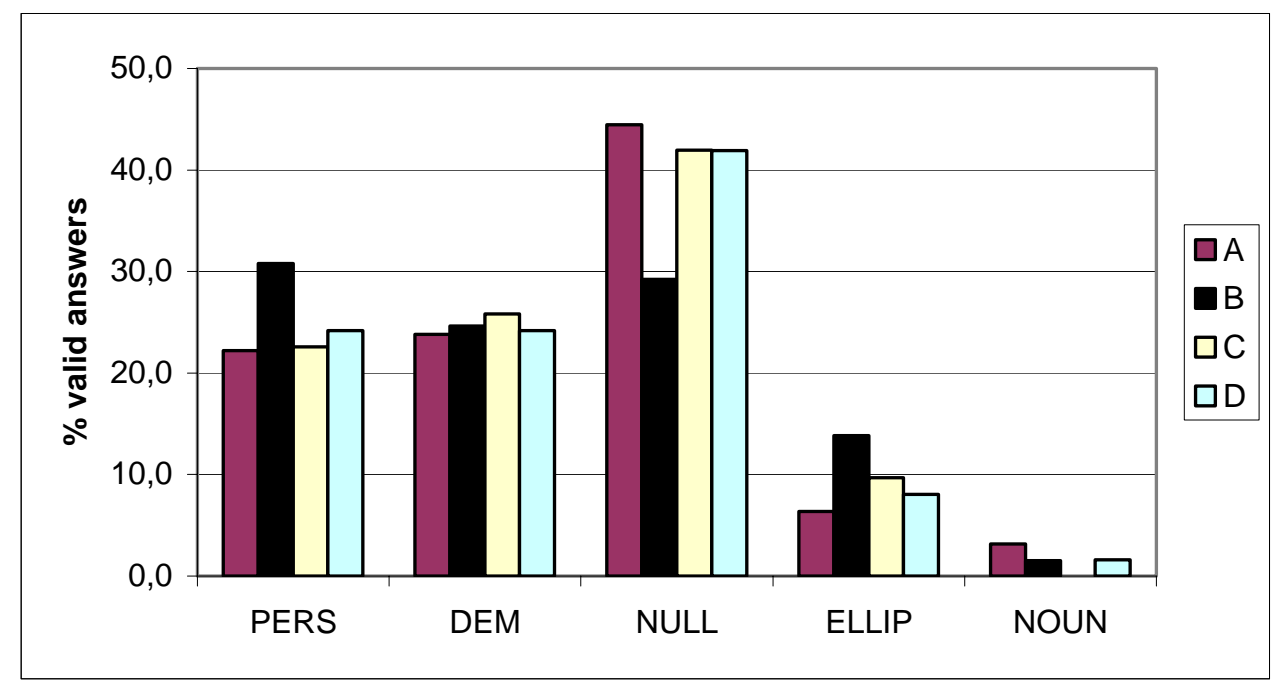

Figure 5: Production pattern of group 1 (mean age of 3;0)

The production of null pronouns in sentence B differs significantly from this pattern, which means that their rate is equal to the production rates of personal and demonstrative pronouns. The non-canonical combination of inanimate subject and an animate object in B seems to influence the production behaviour of the youngest children, prompting them to repeat the pronoun they heard or to leave out the pronoun completely, often producing minimal elliptic sentences.

The repetition pattern of group 2 (mean age of 3;6) shows no significant influence of sentence type and no preference for a pronominal type in the production pattern (see Figure 6). The repetition rates of all pronouns approach similar levels. 


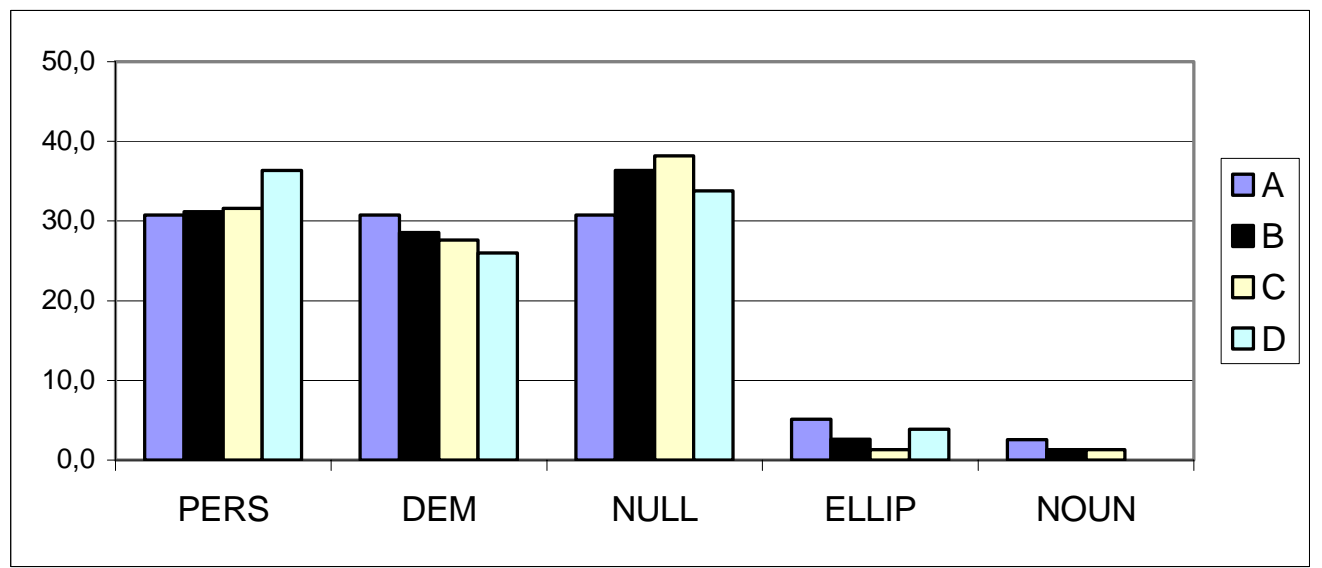

Figure 6: Production pattern of group 2 (mean age of 3;6)

In sentence A, group 3 (mean age 4;0) shows rates of subject drop (Wilcoxon $(2,32) \mathrm{z}=-2.862 ; \mathrm{p}<.004$ ) and of personal pronouns (Wilcoxon ${ }_{(2,32)} \mathrm{z}=-2.598$; $\mathrm{p}<.009)$ which are significantly higher than the rate of demonstrative pronouns. The rates of the 3 pronominal types are levelled in condition $\mathrm{D}$, while the rate of elliptic productions in it increased.

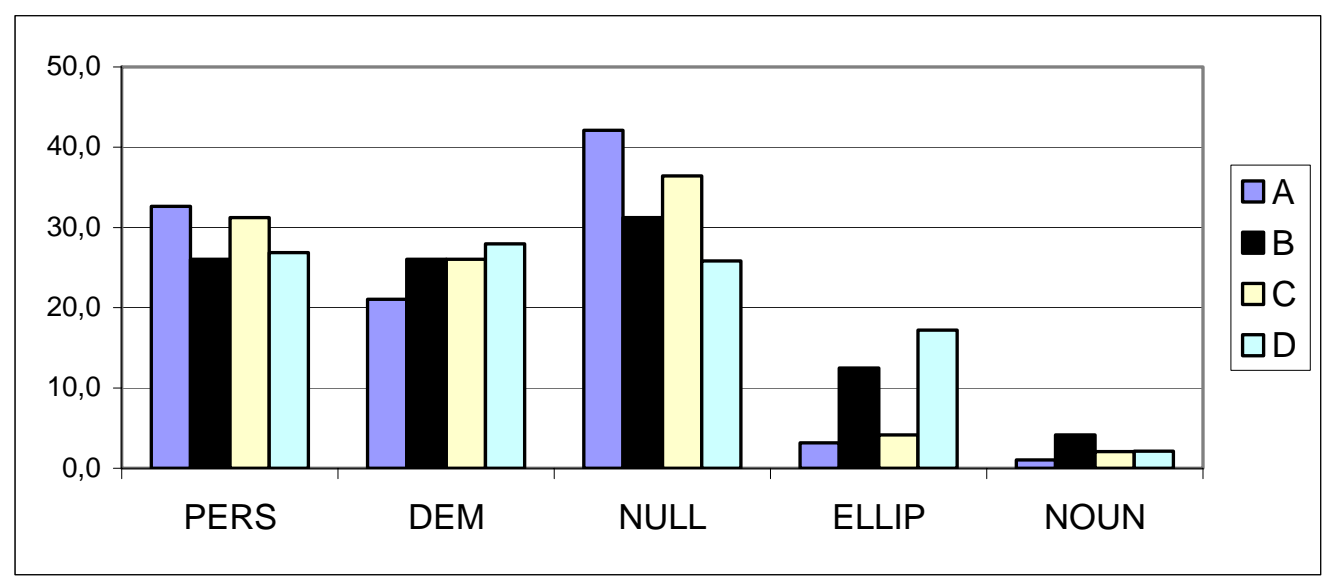

Figure 7: Production pattern of group 3 (mean age of 4;0)

The production pattern in group 4 (mean age of 4;6) shows high scores of correct repetitions for each given pronoun type. There are no differences in the production rates of the pronoun types in the four sentence categories.

In the last age group, the 5-year-old children exhibit a different production behaviour for sentence A when compared to all other sentences. In a context featuring two animate referents, the 5-year-olds preferably produce personal (Wil$\operatorname{coxon}_{(2,31)} \mathrm{z}=-2.271 ; \mathrm{p}<.023$ ) and null pronouns (Wilcoxon $(2,31) \mathrm{z}=-2.333$; $\mathrm{p}<.020)$ and avoid demonstratives. The increase of noun production is also related to the overall tendency for demonstratives to become substituted by nouns. 


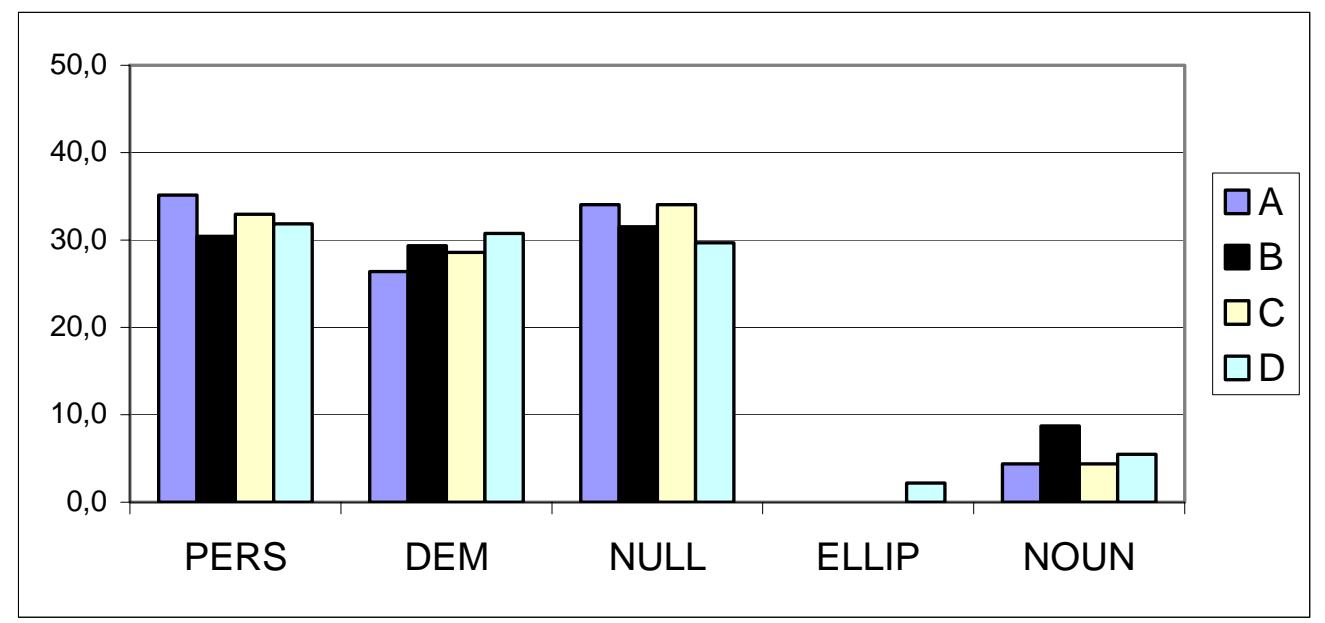

Figure 8: Production pattern of group 5 (mean age of 5;0)

To sum up, we found a developmental change in the use of the three tested pronominal types. The initial phase is characterised by an overuse of subject-drop. Later on the children gradually adjust their use of null pronouns to contexts in which there are animate subjects as antecedents. The same is true for the personal pronouns. The production pattern found in sentence A confirms the hypothesis that Bulgarian children rely on the animacy of referents to select an appropriate pronominal form. While personal and null pronouns are the preferred choice, the children start avoiding demonstrative pronouns when both referents are animate, at an age of approximately 4 years.

The production of elliptic utterances seems characteristic for sentence D, in which the animacy cue is supported by the grammatical role. With respect to their repetition behaviour, 4-year-old children tend to produce elliptic utterances as substitutes for utterances with subject-drop. A second relevant observation concerns the distribution of elliptic utterances and the substitution of the anaphoric pronouns by a nominal phrase. The rates of these answer types stand in a reciprocal relation to each other. With increasing age, the children learn that minimising the utterance is not the appropriate behaviour in ambiguous contexts, and that the use of more explicit expressions (nouns and nominal phrases) guarantees the communication success.

\section{Sentence comprehension}

In order to establish a comparison base against which the comprehension of the children can be evaluated, we will first discuss the way Bulgarian adults perceive the situations presented in the 4 sentence types and the role of anaphoric pronouns as disambiguation cues. Afterwards we will present analyses and a discussion of child comprehension targeting the investigated referential features, pronominal resolution and age effects. 


\subsection{Analysis and discussion of adult anaphora resolution}

In the production part, the adult participants achieved a correct repetition score of $99.7 \%$. The failure quote is due to one participant who did not produce two stimuli clauses. Given the complete correspondence between given stimuli and produced pronouns, the main goal will be the evaluation of disambiguation strategies according to the pronouns given in the 4 types of stimuli sentences.

The first analysis concerns the comprehension pattern in the four sentence types. The results of $4 \times 3$ ANOVA with the factors SENTENCE TYPE (A, B, C, D) and PRONOUN TYPE (PERS, DEM \& NULL) reveal a significant effect of sentence type $\left(\mathrm{F}_{(3,467)}=20.082 ; \mathrm{p}<.000\right)$, but no effect of the pronoun type and no interactions.

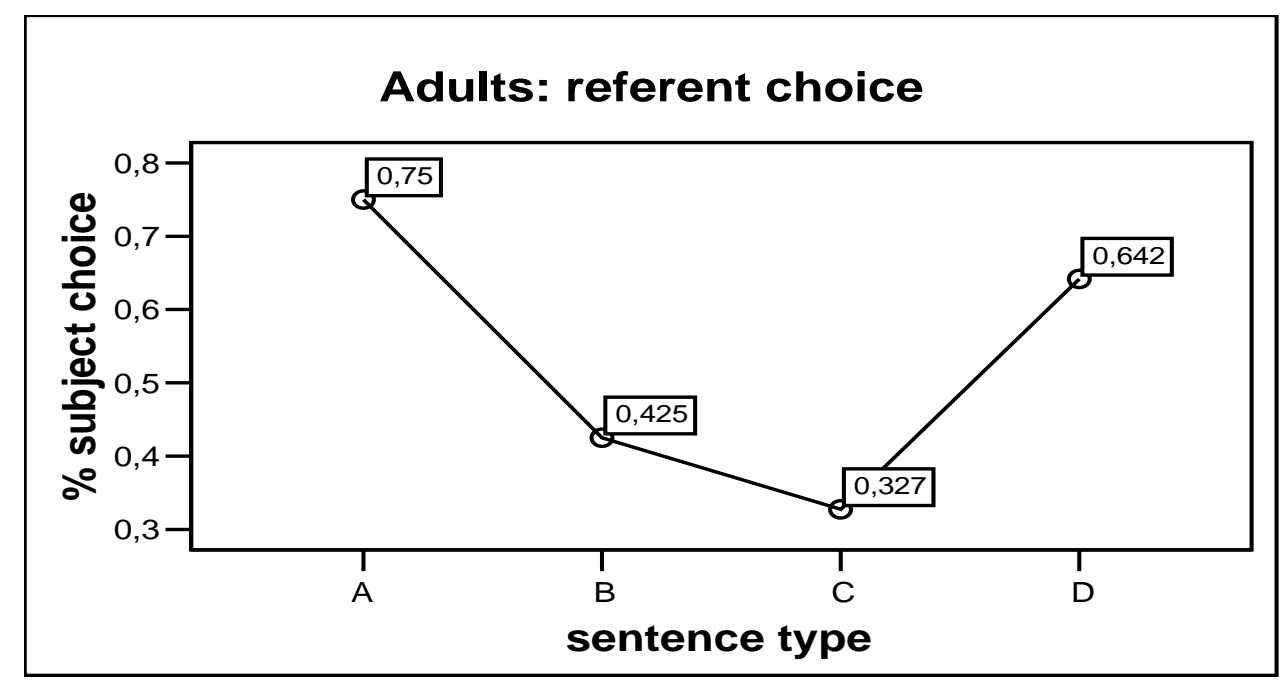

Figure 9: Adults - comprehension pattern in the sentences

In a fine-grained ANOVA with the factors SUBJECT ANIMACY, OBJECT ANIMACY and PRONOUN TYPE, we see a main effect of SUBJECT ANIMACY $\left(\mathrm{F}_{(1,467)}=54.629\right.$, $\mathrm{p}<.000)$ and OBJECT ANIMACY $\left(\mathrm{F}_{(1,467)}=5.671 \mathrm{p}<.018\right)$, but no effect of the given PRONOUN TYPE and no interactions. From Figure 9 we see that a referent is likely to be chosen if it is animate and the more so if it is a subject at the same time.

For all stimuli taken together, we do not find an effect of the given pronoun, but a strong effect of the referential properties in their 4 possible combinations. In what follows we analyse the disambiguation power of the given pronoun types within the four sentence types separately (see relevant numbers in Table 3). 


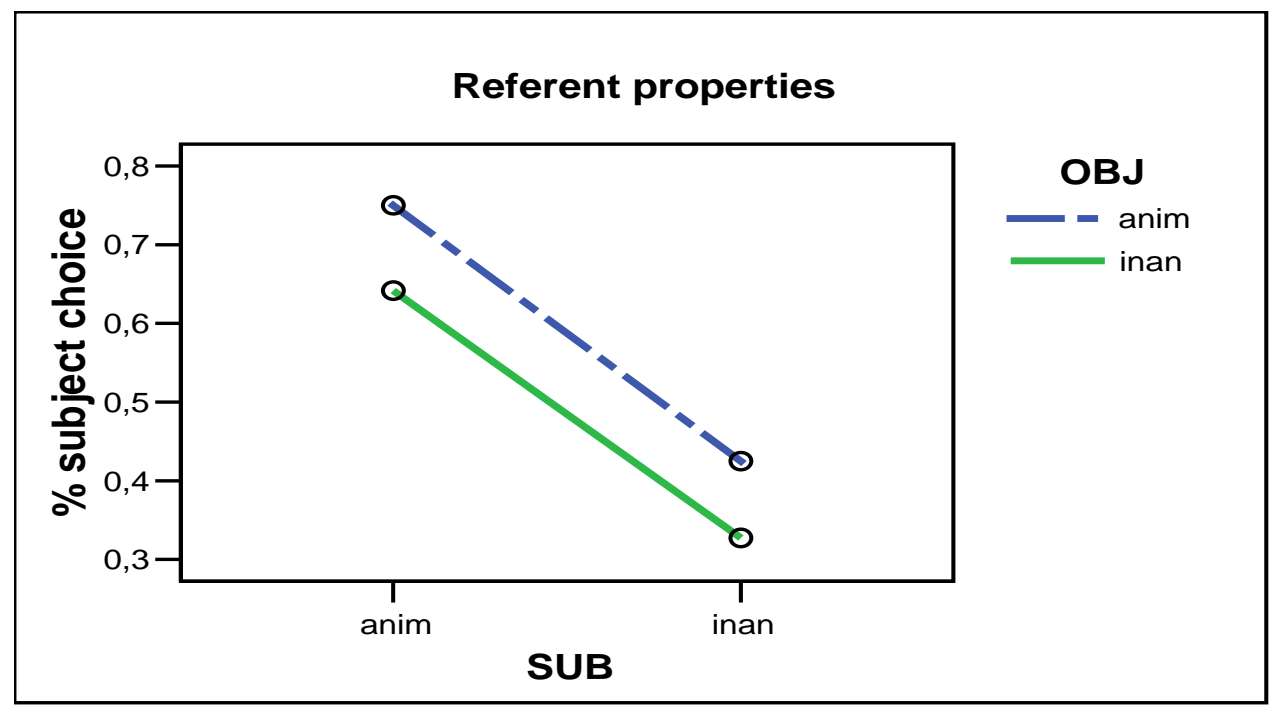

Figure 10: Main effects of subject and object animacy

Sentence A is not comprehended as an ambiguous one by the adult speakers of Bulgarian. In a one-sample t-test (2-sided, df 19) comparing the choice behaviour against the chance level $(50 \%)$, all three pronouns were reliably (PERS: $\mathrm{p}<.000$; DEM: $\mathrm{p}<.017$; NULL: $\mathrm{p}<.002)$ disambiguated to the animate subject. In setting B we observe that the choice between subject and object as antecedents of the used anaphora remains at chance level.

Table 3: Anaphora resolution depicted by the rate of chosen antecedent subjects

\begin{tabular}{|c|c|c|c|c|}
\hline & A & B & C & D \\
\hline $\begin{array}{l}\text { given } \\
\text { pronoun }\end{array}$ & $\begin{array}{r}\text { animate SUB } \\
\text { animate OBJ }\end{array}$ & $\begin{array}{r}\text { inanimate SUB } \\
\text { animate OBJ }\end{array}$ & $\begin{array}{c}\text { inanimate SUB } \\
\text { inanimate OBJ }\end{array}$ & $\begin{array}{r}\text { animate SUB } \\
\text { inanimate OBJ }\end{array}$ \\
\hline PP & $78 \%$ & $45 \%$ & $30 \%$ & $70 \%$ \\
\hline DP & $70 \%$ & $40 \%$ & $40 \%$ & $55 \%$ \\
\hline NULL & $78 \%$ & $43 \%$ & $28 \%$ & $68 \%$ \\
\hline
\end{tabular}

For sentence $\mathrm{C}$ featuring two inanimate referents, we expected the factor grammatical role to be decisive for pronominal disambiguation in the same way as in sentence A. However, in the sentences with anaphoric subject-drop $(p<.009)$ or with a personal pronoun $(\mathrm{p}<.017)$, the referent choice clearly goes to the object. Sentences containing a demonstrative pronoun lead to a random referent choice. In setting $\mathrm{D}$, depicting the prototypical constellation of an animate subject and inanimate object, the disambiguation function of the used pronominal anaphora is slightly less pronounced than expected. The personal pronoun and the null pronoun refer to the animate subject. The demonstrative pronoun remained at chance level as in sentences B and C. 
To sum up, the 4 settings differ with respect to the referent choice, the main factor being the presence of an animate subject. The participants understand personal pronouns and null pronouns as referring to animate subjects if there are any, as in settings A and D. In settings lacking an animate subject, personal and null pronouns show sensitivity to the animacy of the object. If both referents are inanimate, personal and especially null pronouns are resolved to the object of the antecedent clause. The presence of an animate object in sentence B results in a chance level referent choice. Sentence B represents a constellation of conflicting cues, animacy and grammatical role guiding the choice in different directions. As there is no interaction between the animacy of subject and objects, we conclude that grammatical role and animacy are perceived by the adult speakers as equally strong cues.

Stimulus sentences with demonstrative pronouns seem to be ambiguous for Bulgarian adults. In sentences B, C and D, the test persons remain at chance level. Sentence A is the only condition in which the preference for the animate subject overrides the unusual use of a demonstrative pronoun. This fact may be accounted for by the alignment of two prerequisites. The first one is that both referents are masculine, thus fulfilling the felicity requirement for the use of a masculine demonstrative pronoun. The second one is the absence of an animacy difference between the referents. In a situation like in $\mathrm{D}$, in which there is a possible inanimate referent, the use of a demonstrative as an expression referring to the animate referent becomes less felicitous.

A demonstrative pronoun always retains its identification function selecting a single referent out of a set whose members exhibit the same features. The use of a demonstrative presupposes the existence of such a set. Given those considerations, the acceptability of demonstrative pronouns in sentence A can be explained by the possibility to perceive the quite similar animate referents (e.g. tiger and lion) as building a set. In contrast, the animacy difference in D prevents the constitution of a set, needed for the felicitous use of a demonstrative pronoun.

\subsection{Analysis and discussion of child comprehension}

In this section we investigate the influence of the antecedents' animacy and syntactic role on the way children understand pronouns as anaphoric expressions. The first analysis concerns the referential choice of all age groups together. It targets the assumed ranking of referent features which are possibly used by the children for co-reference establishment.

We computed a $3 \times 4$ ANOVA on the percent choice of subjects (or first mentioned referents) with the factors GIVEN PRONOUN TYPE (PERS, DEM \& NULL) and SENTENCE TYPE (A, B, C, D). We found a main effect of the factor sentence 
type $\left(\mathrm{F}_{(1,1744)}=56,47 ; \mathrm{p}<.0000\right)$, but no effect of the factor pronoun type given in the anaphoric sentence. In Figure 11 we see that children alter their referential choice according to the different combinations of referent properties. Tukey's post hock comparison reveals significant differences between all sentence type pairings except for the sentences $\mathrm{B}$ and $\mathrm{C}$.

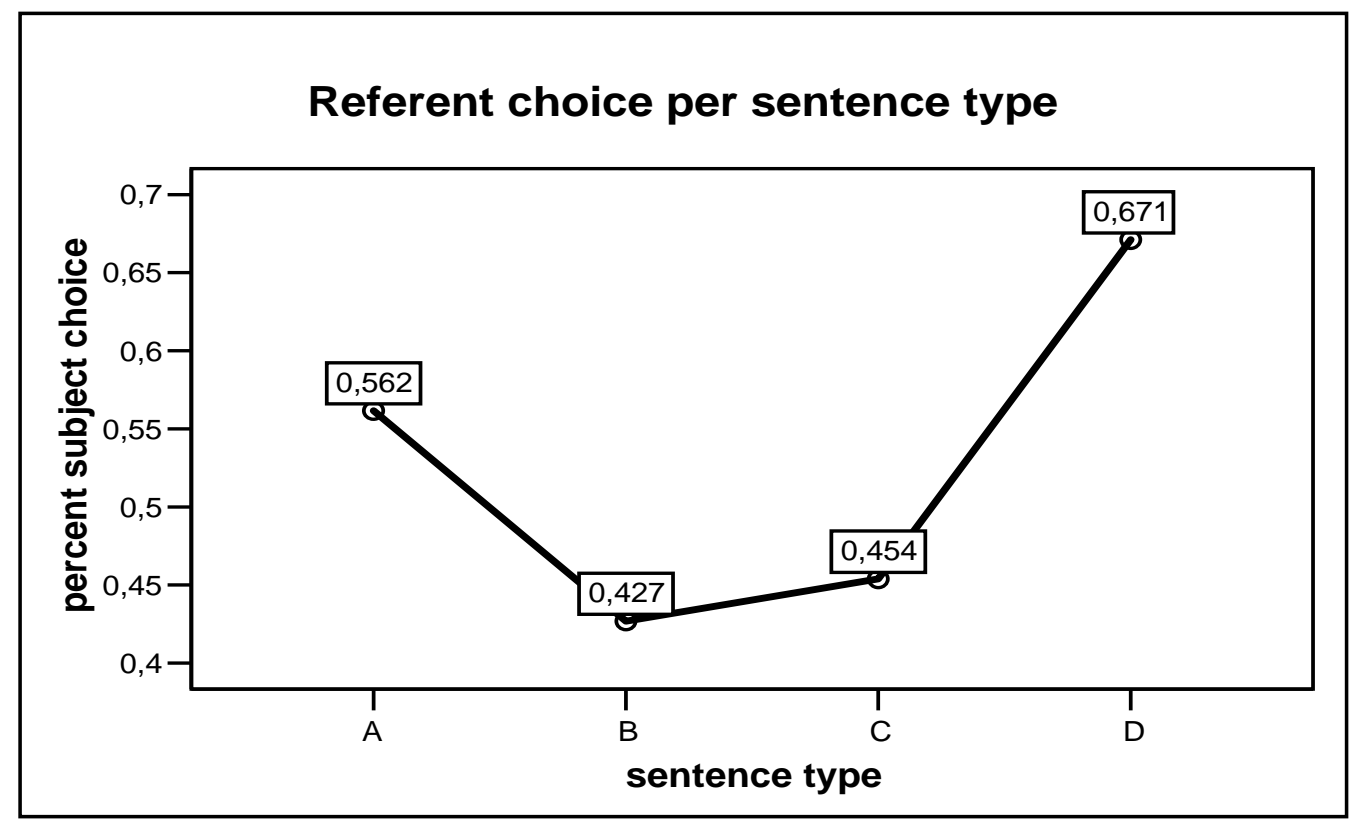

Figure 11: Children - comprehension pattern

In the following, we present a more detailed ANOVA analysis of children's comprehension with the factors ANIMACY and GRAMMATICAL ROLE of the antecedents. We see a main effect of SUBJECT ANIMACY $\left(\mathrm{F}_{(1,1744)}=56.47 ; \mathrm{p}<.000\right)$. OBJECT ANIMACY plays a significant role for the co-reference establishment as well $\left(\mathrm{F}_{(1,1744)}=8.49 ; \mathrm{p}<.004\right)$. The possible combinations of SUBJECT and OBJECT ANIMACY have different impact on the referent choice as revealed by their interaction just approaching significance $\left(\mathrm{F}_{(1,1696)}=3.34 ; \mathrm{p}<0.067\right)$. In sentences of the A type in which both antecedents are animate, the referent choice goes to the subject. If both antecedents are inanimate as in the mirror condition $\mathrm{C}$, the children tend to choose the object, but remain at chance.

In sentences $\mathrm{B}$ and $\mathrm{D}$ representing mixed conditions of subject and object animacy, we see the effect of conflicting (sentence B) or aligned (sentence D) disambiguation cues. The combination of an animate subject and an inanimate object (D) presents the children with a prototypical feature distribution, and thus with a less ambiguous situation. Accordingly, the children opt for the animate subject in almost $70 \%$ of the time. In the opposite feature combination (B), the animate antecedent, being an object this time, wins over the inanimate subject. 
In sum, the presence of an animate subject is a decisive cue for the resolution of ambiguous pronominal reference, and it is more powerful if there is an animacy difference between the referents.

\subsubsection{Developmental pattern}

The comprehension data comprising the referent choice of all children in the age bracket from $2 ; 10$ to $5 ; 03$ is not homogeneous. The comprehension pattern changes with age as the significant three-way interaction: SUBJECT ANIMACY $\mathrm{x}$ OBJECT ANIMACY X AGE GROUP $\left(\mathrm{F}_{(4,1696)}=5.59 ; \mathrm{p}<.000\right)$ of the computed ANOVA reveals. Figure 12 shows the different effects of the selected factors on the reference establishment in each of the 5 tested age groups.

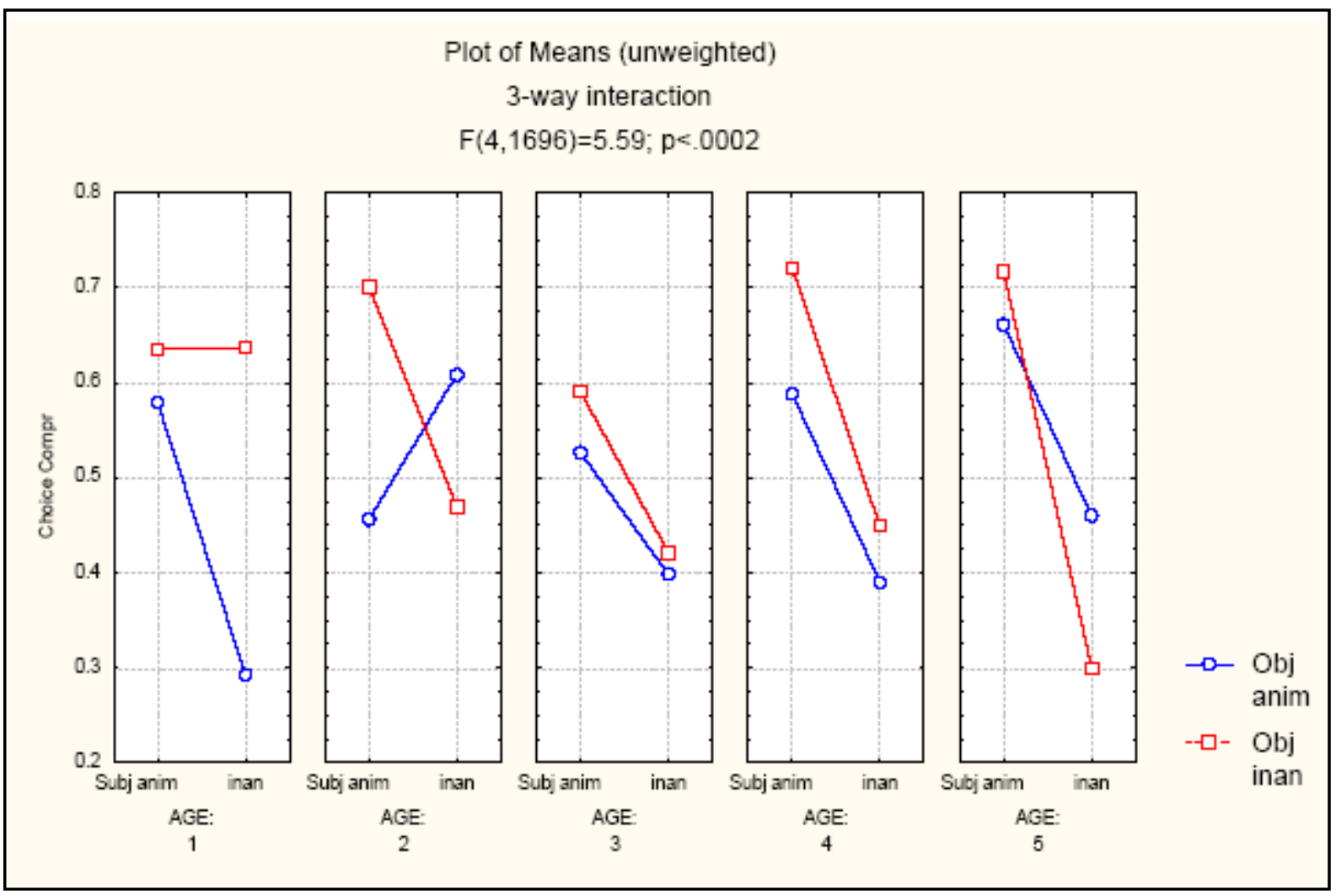

Figure 12: Threefold interaction of age group, subject and object animacy

In the following, we present separate analyses for each of the 5 age groups targeting the effects of the factors SUBJECT ANIMACY, OBJECT ANIMACY and PRONOUN on the referential choice measured again as percentage of chosen subject antecedents.

For the youngest age group (mean age 3;0), we found main effects of both SUBJECT ANIMACY $\left(\mathrm{F}_{(1,341)}=7.73 ; \mathrm{p}<.0057\right)$ and OBJECT ANIMACY $\left(\mathrm{F}_{(1,341)}=15.11\right.$; $\mathrm{p}<.0001)$, and a significant interaction between them $\left(\mathrm{F}_{(1,431)}=5.59 ; \mathrm{p}<.005\right)$, but no effect of the given pronoun type. When the subject is animate, the animacy of 
the object noun does not influence the referent choice. When the subject is inanimate, then there is a significant difference between choices in conditions with animate object as in B and inanimate objects as in C. The youngest tested children show a clear animacy effect in sentence $\mathrm{B}$ in which the animate object wins. Sentence B differs from all other conditions as it presents a situation which is resolved easily by the children - triggering an above chance performance ( $71 \%$ object choices). In condition $\mathrm{C}$, the children opt for the subject antecedent, the proportion of chosen inanimate subjects being the same as of the animate subjects in sentence $\mathrm{D}$. The youngest children seem to rely on a hierarchy of referential features which is headed by animacy and followed by subject as syntactic role.

Separate $\chi^{2}$ tests targeted the disambiguation functions of the three pronominal types given in each of the four sentences. In sentences $\mathrm{A}$ and $\mathrm{C}$, the children remain at chance level independent of the given pronoun type. In sentence $\mathrm{B}$ demonstrative $\left(\chi_{(1,30)}^{2}=6.5 ; \mathrm{p}<.01\right)$ and null pronouns are resolved to the animate object $\left(\chi_{(1,30)}^{2}=5.8 \mathrm{p}<.016\right)$. The personal pronoun narrowly misses significance $(\mathrm{p}<.068)$.

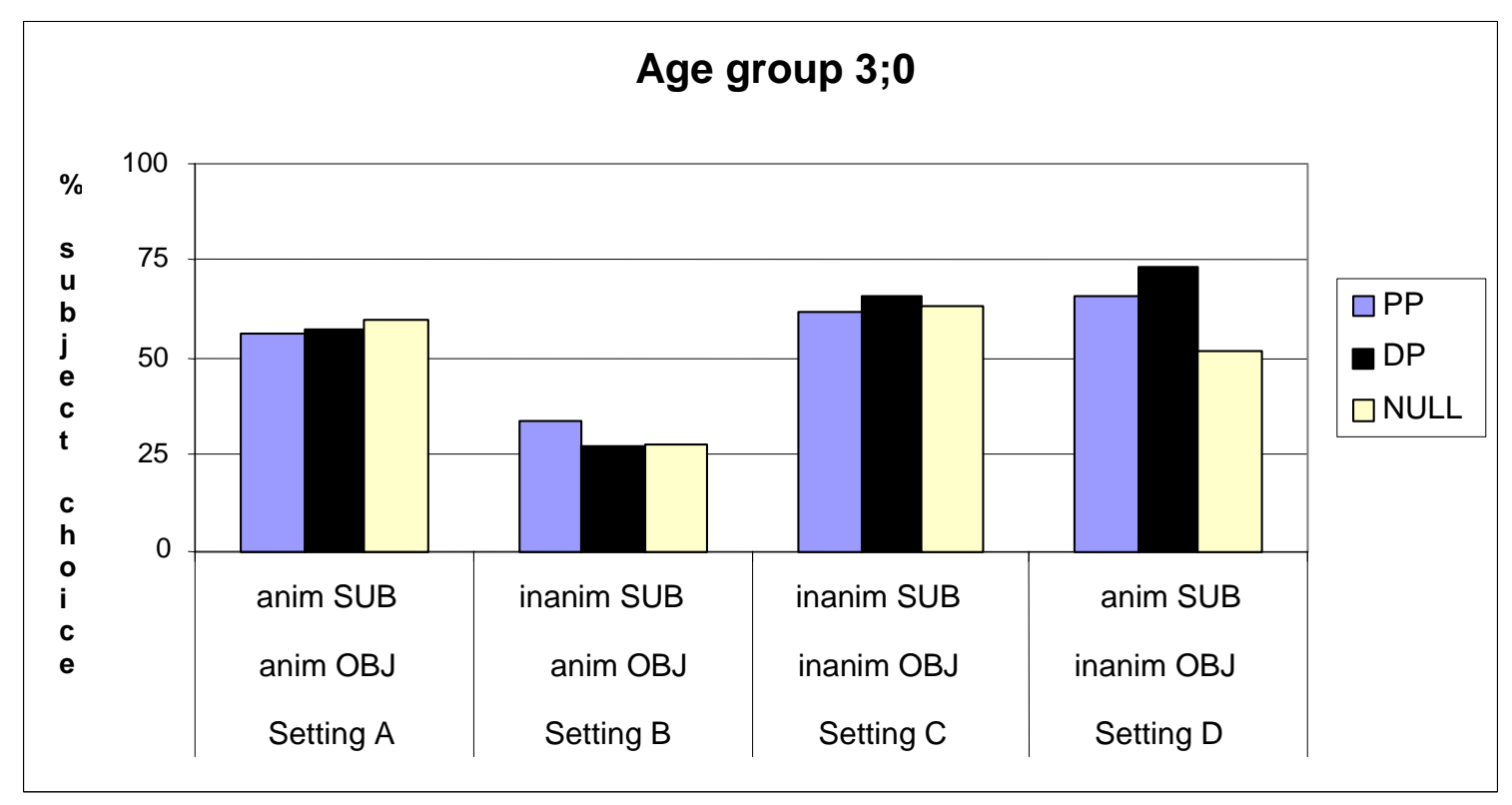

Figure 13: Pronominal co-reference at the age of $3 ; 6$

In setting $\mathrm{D}$ presenting the opposite cue combination only the demonstratives clearly pattern with the animate subject $(\mathrm{p}<.01)$. The direct comparison between $\mathrm{B}$ and $\mathrm{D}$ shows a significant preference for the animate referent, particularly clearly when children are presented with a demonstrative pronoun.

Taken together the results suggest that children initially rely on the factor animacy when resolving a pronoun. The behaviour of the demonstrative pro- 
noun suggests that the children interpret it more deictically, as pointing to the most salient referent.

The children in group 2 (mean age 3;6) do not use the same disambiguation strategy as the 3-year-olds. There are no main effects of SUBJECT and OBJECT ANIMACY, but a significant interaction between them. When the subject is animate, the co-reference establishment depends on the animacy feature of the object.

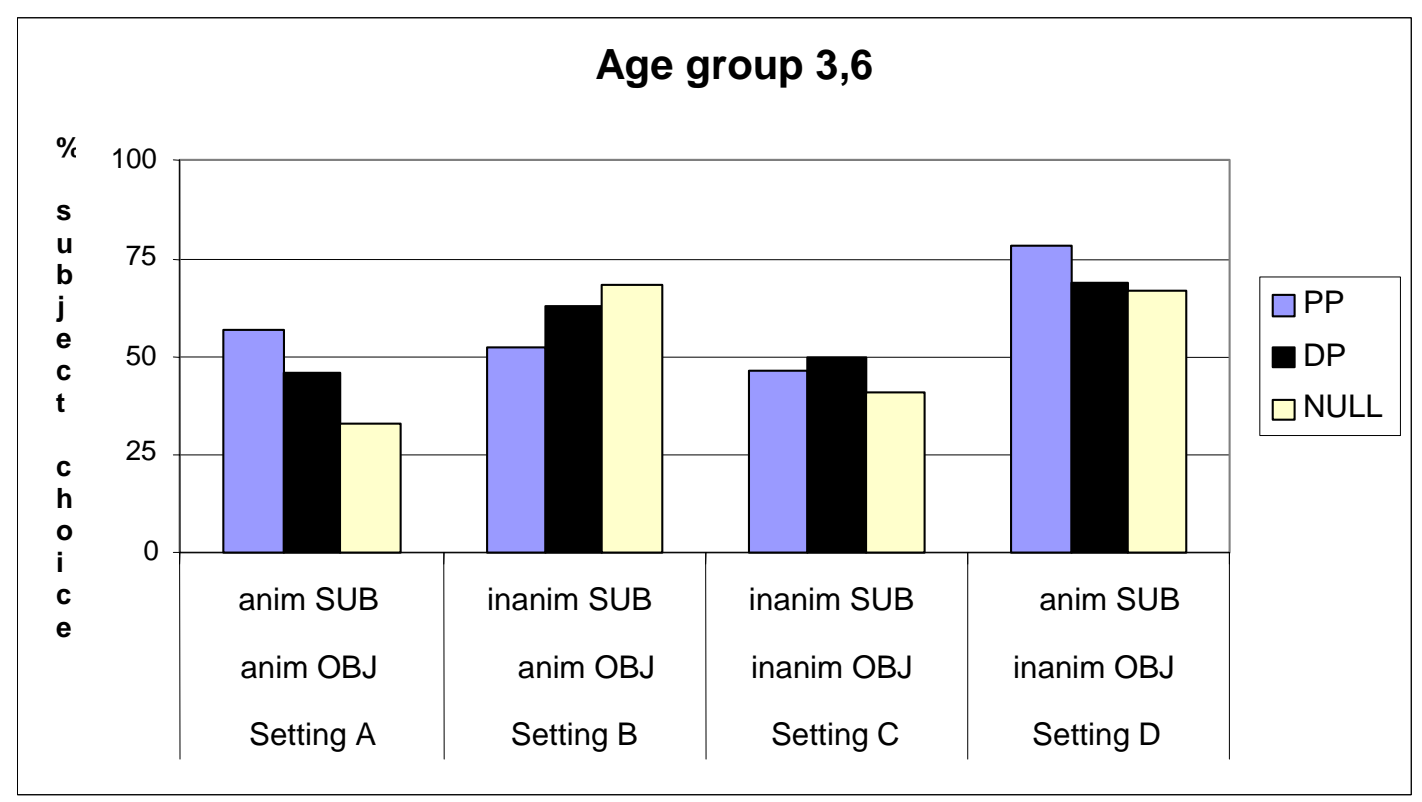

Figure 14: Pronominal co-reference at the age of $3 ; 6$

If the animate subject has a distinct animacy value from the object (the object is inanimate), then the animate subject wins as pronominal antecedent. If there is no animacy cline, the referent choice remains at chance level. The children perform best in the less ambiguous sentence $\mathrm{D}$. In the opposite cue configuration of sentence $\mathrm{B}$, they are at chance, no longer preferring the animate object. The children also show a chance behaviour in sentence $\mathrm{A}$ and $\mathrm{C}$, in which the animacy cue is neutralised and the syntactic role does not suffice as referent indicator. The weakening of the subject position as a disambiguation cue results in an overall chance performance, apart from sentence $\mathrm{D}$ which still preserves the subject preference due to the animacy factor.

For age group 2, the personal pronoun does not influence the referent choice except for condition $\mathrm{D}$ in which it unambiguously refers to the animate subject $\left(\chi_{(1,28)}^{2}=8.33 ; \mathrm{p}<.004\right)$. The same is true for the demonstrative pronoun which points to the subject in $\mathrm{D}(\mathrm{p}<.050)$. Null pronouns tend to be associated with animate objects in sentences $\mathrm{A}, \mathrm{B}$ and with animate subjects in $\mathrm{D}$, but miss significance $(p<.08$ in $A$ and $D$ and $p<.059$ in $B)$. 
The situation of transition becomes more pronounced in age group 3 (mean age of $4 ; 0)$. The only relevant factor is SUBJECT ANIMACY $\left(\mathrm{F}_{(1,364)}=8.35\right.$; $\mathrm{p}<.0041)$, no other effects or interactions hold significance here. While in sentence A the children are clearly at chance level - 53\% subject choice - in sentence $\mathrm{C}$ a shift towards an object choice becomes apparent. Although the rate of chosen subject in $\mathrm{D}$ is not very high (59\%), there is still a significant difference to sentence $\mathrm{B}$, in which the preference for the object aligns with the animacy cue.

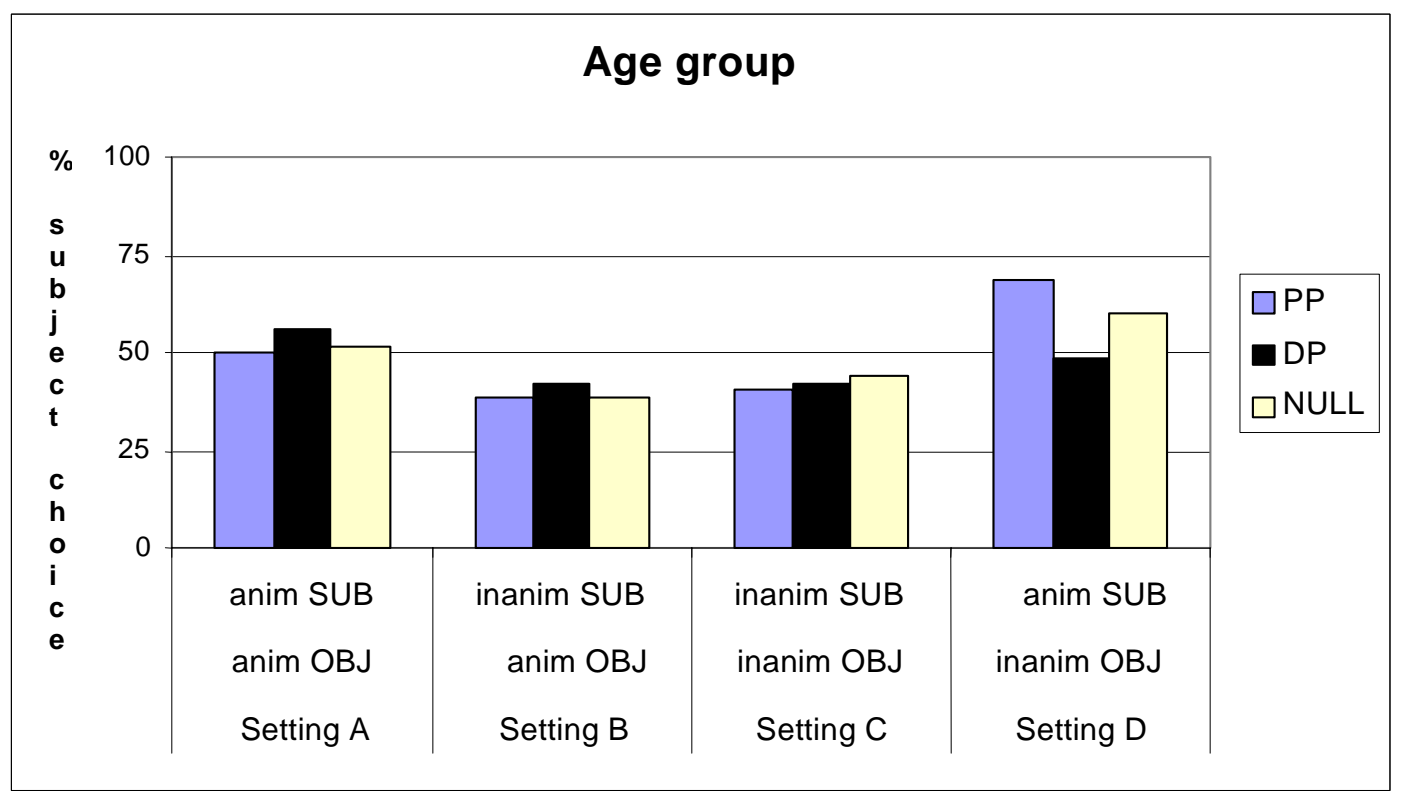

Figure 15: Pronominal resolution at the age of $4 ; 0$

The single pronoun conditions reflect the overall difficulties of the 4-year-olds to establish co-reference between the given anaphoric pronoun and a possible antecedent. Only the personal pronoun is associated with the animate subject in condition $\mathrm{D}\left(\chi_{(1,32)}^{2}=4.5 ; \mathrm{p}<.034\right)$ in all other conditions the children remain at chance independently of the given pronoun.

In group 4 (mean age $4 ; 6$ ) we find a main effect of SUBJECT ANIMACY $\left(\mathrm{F}_{(1,335)}=20.06 ; \mathrm{p}<.0000\right)$ and a marginal effect of OBJECT ANIMACY $(\mathrm{p}<.07)$, but no interaction between them. Sentence $\mathrm{D}$ is recognized as the most unambiguous situation, the pronoun is assigned to the animate subject antecedent. The influence of the factor syntactic role is shifted back to the subject, as it becomes more strongly associated with the prototype of an animate agent - the proportion of subject choices in sentence $\mathrm{A}$ increases again. In the cases lacking animate subjects (B and $\mathrm{C}$ ), objects are gaining attention but their proportions are still not significantly higher that the rates of subject choices. The animate objects are slightly preferred over the inanimate ones. 


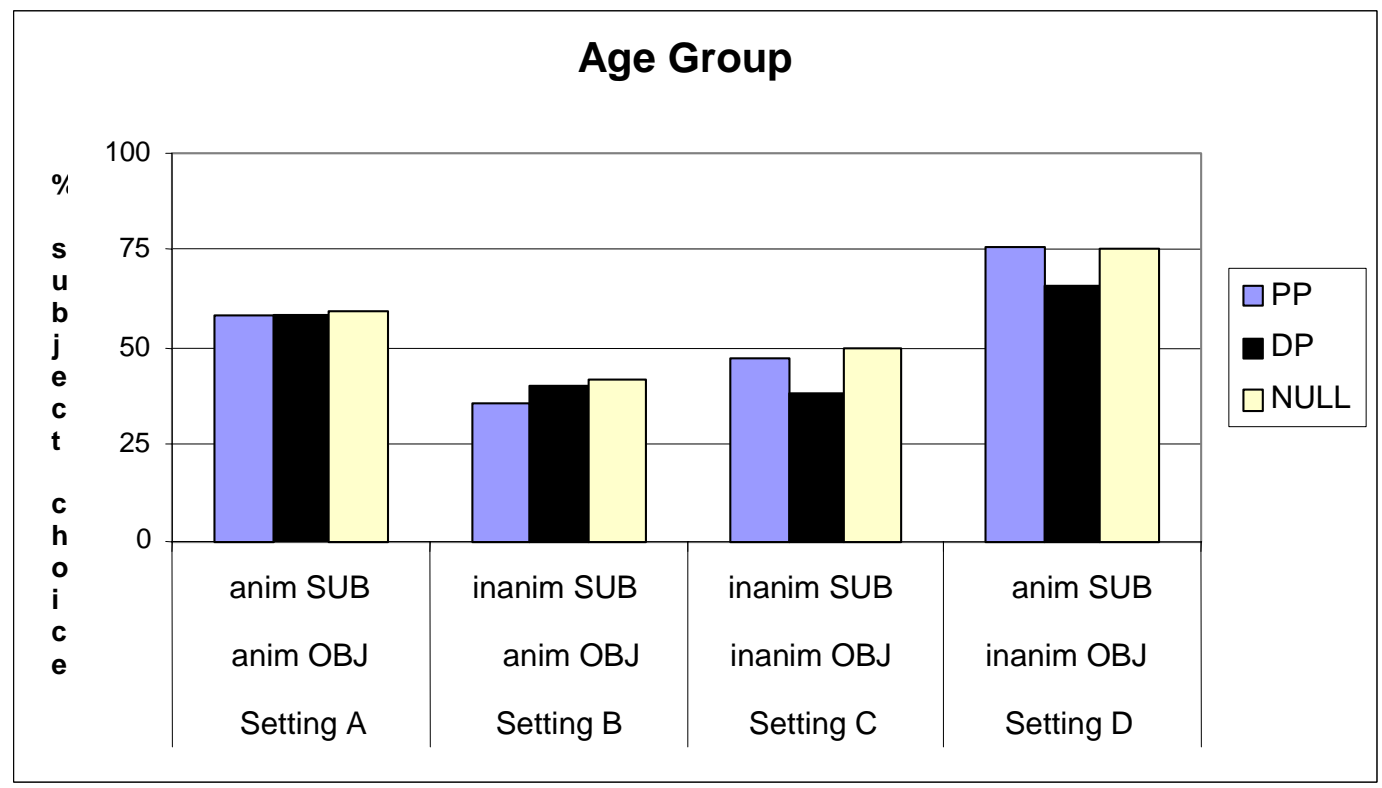

Figure 16: Pronominal resolution at the age of $4 ; 6$

The children still don't rely on the different types of pronouns as a disambiguation signal. No significant differences between the understandings of the three pronouns are found in sentences $\mathrm{A}, \mathrm{B}$ and $\mathrm{C}$. In sentence $\mathrm{D}$, the null pronoun $\left(\chi_{(1,28)}^{2}=7.0 ; p<.008\right)$ becomes established as referring to the animate subject in the same way as the personal pronoun $\left(\chi_{(1,29)}^{2}=7.7 ; \mathrm{p}<.005\right)$, the demonstrative pronoun doesn't reach significance $(\mathrm{p}<.095)$.

Group 5 (mean age of 5;0) exhibits a comprehension pattern which resembles the adult's behaviour. We find a main effect of SUBJECT ANIMACY $\left(\mathrm{F}_{(1,340)}=37.35 ; \mathrm{p}<.000\right)$ and a significant two-way interaction with OBJECT ANIMACY $\left(\mathrm{F}_{(1,340)}=4.54 ; \mathrm{p}<.034\right)$. In the conditions with animate subjects (A and $\mathrm{D})$, the pronoun co-reference is established unambiguously to the animate subject. In sentence $\mathrm{C}$, the five-year-olds clearly choose the object. The object preference in B does not reach significance. When no prototypical animate subject is available, the children resolve the pronoun to the prototypical object, the inanimate one. Now, sentence B becomes the most ambiguous one, as it is deficient in terms of prototypical referents, containing an inanimate subject and an animate object. 


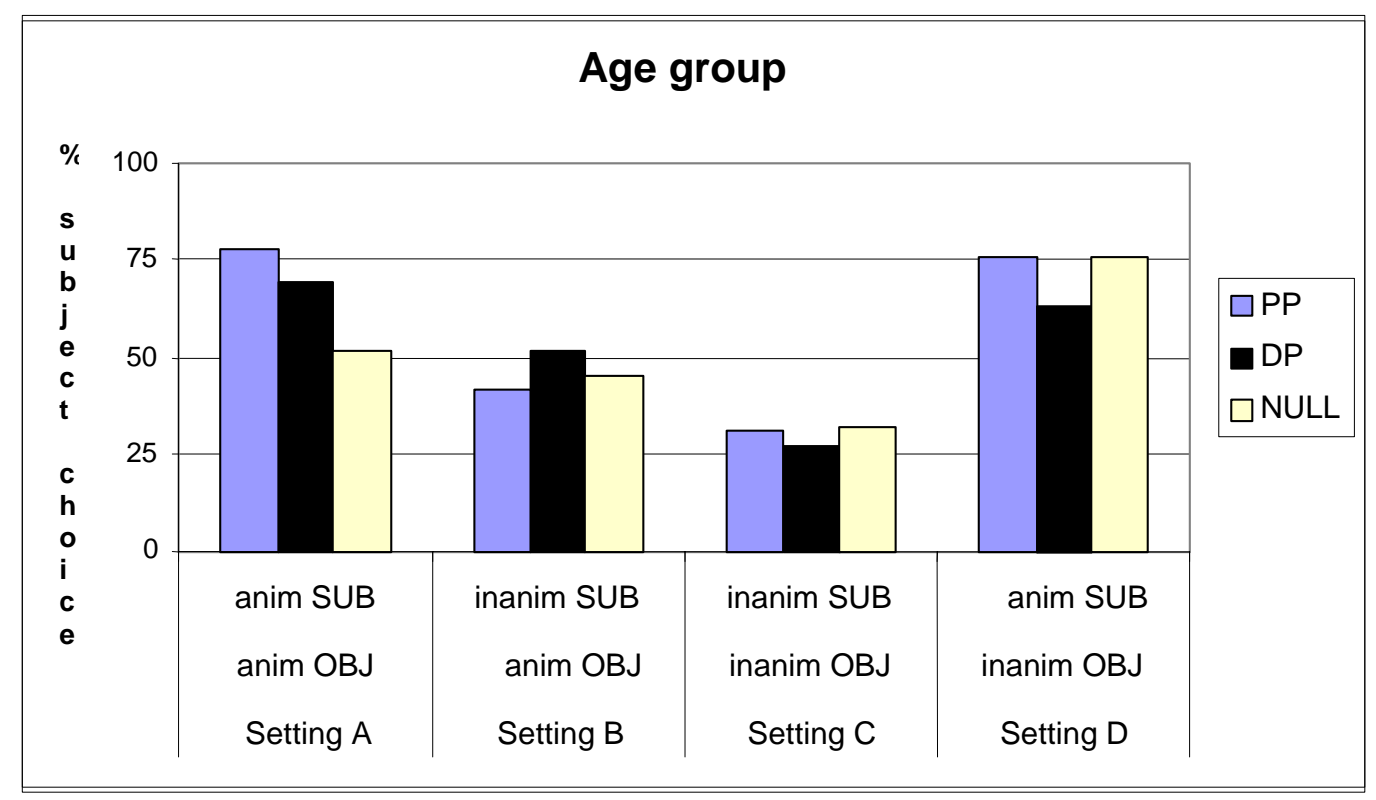

Figure 17: Pronominal resolution at the age of $5 ; 0$

For the 5-year-old children, a match between a personal pronouns and an animate subject can be observed, as it becomes clear from the significant disambiguation effect of the personal pronoun in sentence $\mathrm{A}\left(\chi_{(1,27)}^{2}=8,3 ; \mathrm{p}<.004\right)$, as well as in sentence $\mathrm{D}\left(\chi_{(1,29)}^{2}=7.6 ; \mathrm{p}<.005\right)$. The demonstrative pronouns are understood as referring to the more salient referent, if the children are able to establish such a connection through the antecedent context. The deictic behaviour of the demonstrative pronoun $\left(\chi_{(1,31)}^{2}=6.5 ; \mathrm{p}<.011\right)$ is particularly clear in sentence $\mathrm{C}$ in which the inanimate object seems to be the more accessible antecedent. This referent choice is quite opposite to the animate subjects in sentence D preferred from the age earliest tested. The 5-year-olds start to understand that the null pronoun is used when the referent is not ambiguous. In condition $\mathrm{C}$ the preference moves to the prototypical inanimate object $\left(\chi_{(1,31)}^{2}=3.9 ; \mathrm{p}<.048\right)$. The other factors which may influence the salience of the object in $\mathrm{C}$ will be discussed below.

\subsubsection{Analysis of referent choice according to the produced pronoun}

The next analysis is based on the pronouns which the children actually produced in the repetition task. The results of an ANOVA with the factors SENTENCE TYPE, PRODUCED PRONOUN and AGE GROUP revealed an overall pattern which was not different from the analysis based on the given pronoun types. We found a significant main effect of the SENTENCE TYPE $\left(\mathrm{F}_{(3,1562)}=23.815 ; \mathrm{p}<.000\right)$, and a significant interaction between SENTENCE TYPE and AGE GROUP, but no effects of PRODUCED PRONOUN (see Figure 18) or AGE GROUP, and no other interactions. 


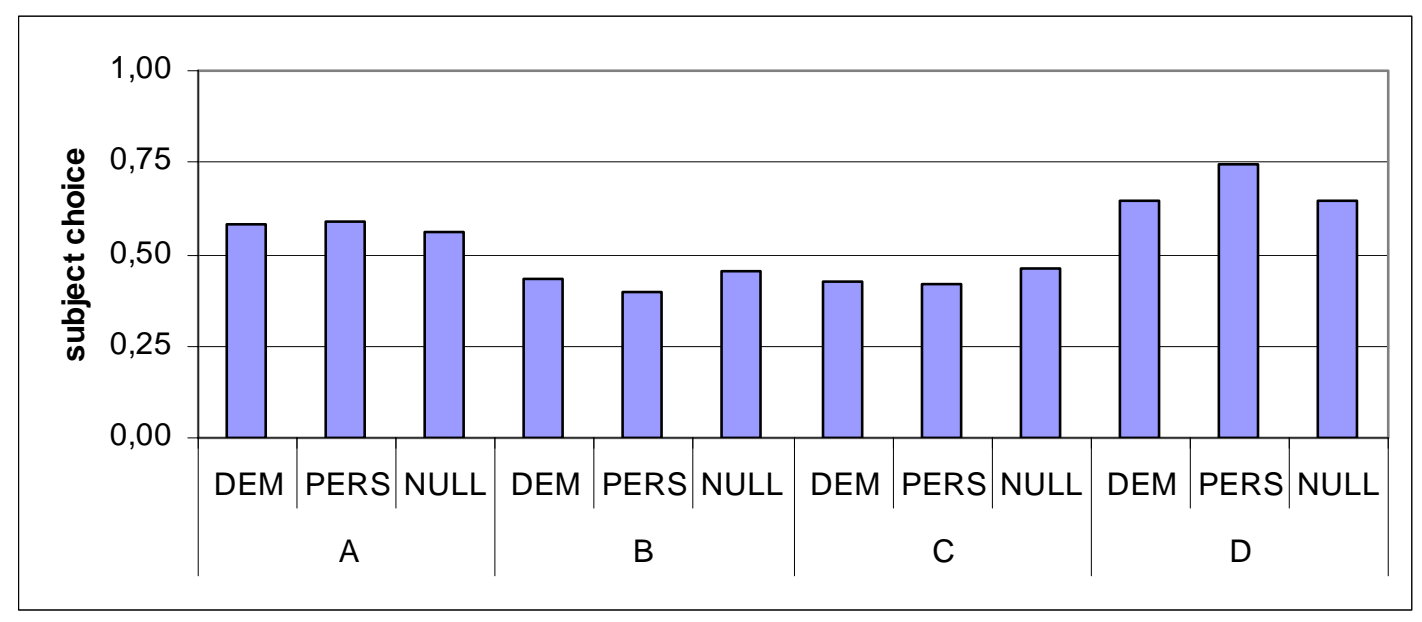

Figure 18: Resolution of produced pronouns

The overall impression is that children have difficulties in understanding null pronouns in the given experimental conditions. The interpretation of elliptic utterances also exhibits an inhomogeneous pattern. The comparison between the resolution preferences of elliptic utterances and such containing subject-drop shows that they often deviate, as for instance in sentence $\mathrm{C}$.

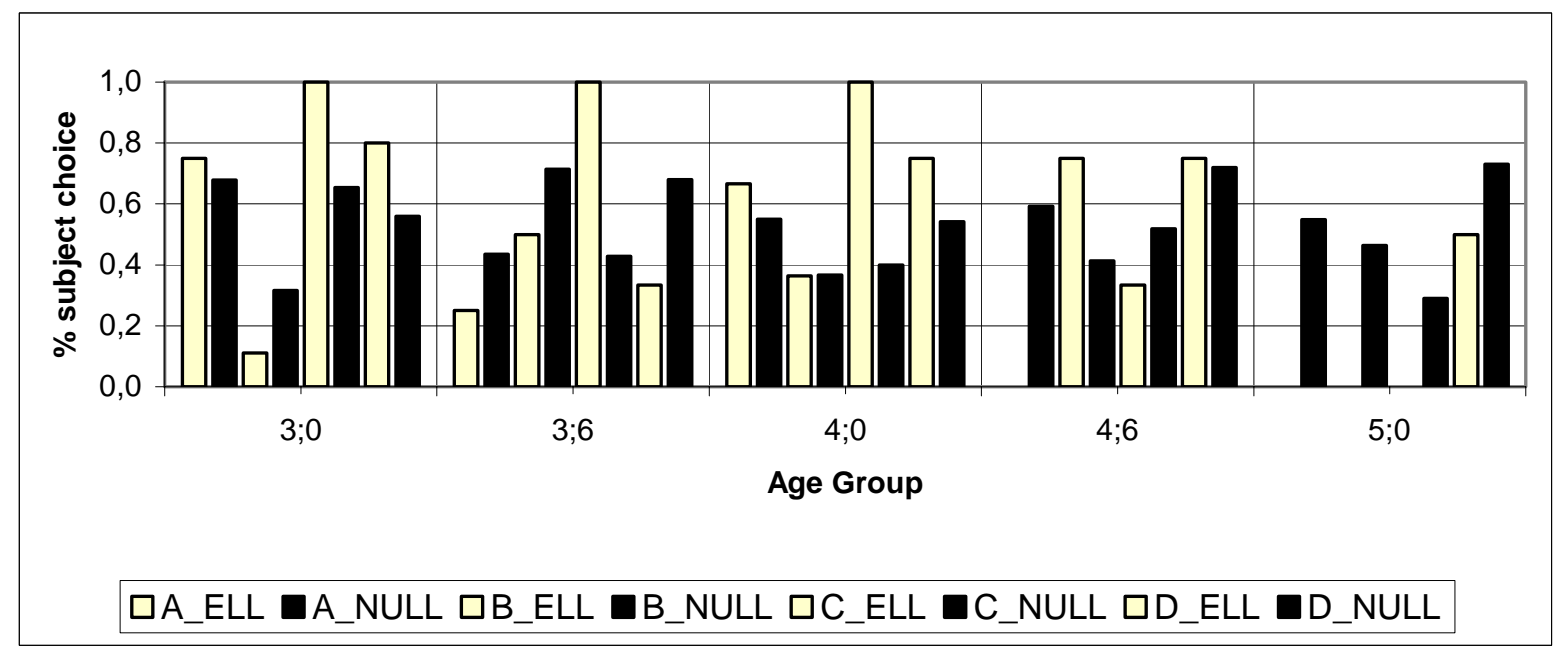

Figure 19: Understanding of ellipses and null pronouns

Up to the age of 4;6, all elliptic utterances in $\mathrm{C}$ are resolved to the subject, while the null pronouns don't show a clear co-reference establishment (see Figure 19).

The difficulties which the children experience when interpreting utterances with subject-drop are especially relevant in sentence A. This antecedent sentence combines two animate referents and seems not to be ambiguous for the adult Bulgarians (see Table 3). Except for the youngest group in which children profit from the joint preference for animate referents and for subjects, all other 
children, even the oldest tested group, remain at chance level in sentence A. Utterances exhibiting subject-drop are reliably resolved to the animate subject only when the children reach the age of 4;6 and in situations presenting at least two aligned cues as in sentence $\mathrm{D}$.

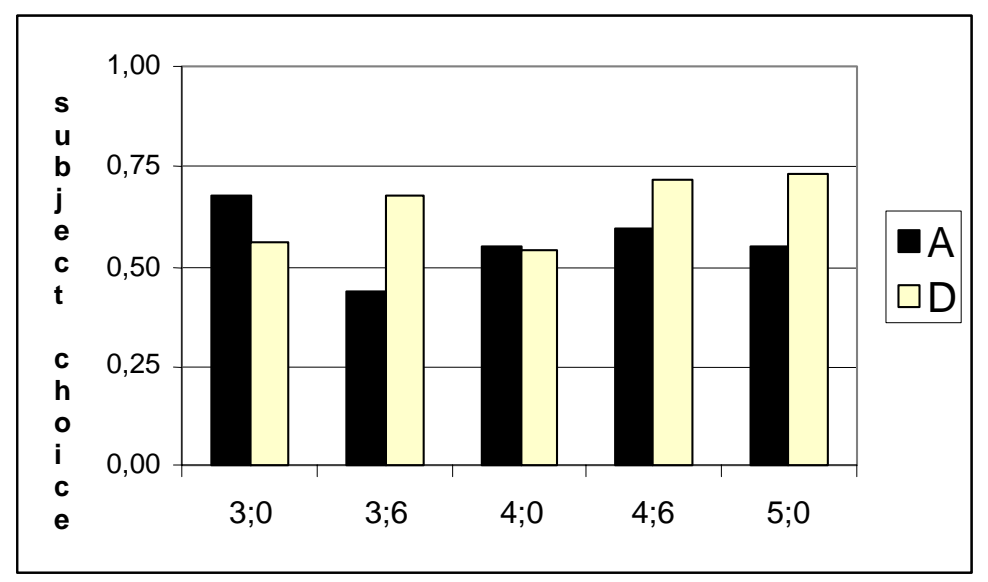

Figure 20: Comprehension of produced null pronouns

In contrast to the difficulties with null pronouns, the children arrive at a stable interpretation of personal pronouns much faster. Their orientation point is the distribution of salience features as represented by the referent in the antecedent context of sentence D.

\section{Conclusion}

The comparison of children's comprehension data and that of the adults reveals a difference with respect to ambiguity perception. The experimental design presents the subjects with stimuli contexts which exhibit a high degree of ambiguity. In order to access the influence of only two salience factors - animacy and grammatical role - the stimuli were deprived of almost all other cues which are jointly at the disposal of the speaker/hearer in every day communication.

Adult Bulgarian speakers navigate in such impoverished contexts using prototypical combinations of referent features. This means that there is no real ranking between the single features animacy and grammatical role. The chance behaviour in sentence B in which the investigated antecedent properties support different referent choices is a clear indicator for this conclusion. A second indicator is found in the unambiguous but reversed referent choice in sentences $\mathrm{A}$ and $\mathrm{C}$, in which animacy is neutralised. Adult speakers look for a prototypical referent, and if there is one, they are able to establish a co-reference relation. In sentence $\mathrm{A}$, the best candidate is the animate subject, in sentence $\mathrm{C}$ it is the inanimate object. As a result, null pronouns are reliably resolved to these referents which are highlighted through their conventionalised feature combination. Con- 
sequently, the referential choice in sentence D is somehow less clear. The percentage of null pronouns resolved to the animate subject decreases slightly, which adds additional support to the common grammar rule that null pronouns are applied only in clear reference relations. In sentence D, the inanimate object increases the ambiguity potential, but still its property of prototypical object cannot override the salience of the animate subject. Although adult Bulgarians do not use demonstrative pronouns as disambiguation cue, the difference between the rates of reference choice achieved for null and personal pronouns on the one hand, and for demonstrative pronouns, on the other is taken as evidence that demonstrative pronouns pattern with the disfavoured referent.

The evaluation of the language acquisition data shows that Bulgarian children do not apply the same disambiguation strategy as adult speakers. The youngest children tested (mean age of 3;0) use a hierarchy of referent features headed by animacy and followed by subject as the preferred grammatical role. This result is in line with the good animacy discrimination abilities of young children found by Mandler (1992) in general, and the prominent role of animate referents at the early stages of co-reference establishment reported in Kuehnast et al. (2007), Bittner and Gagarina, (this volume). However, the pattern of pronominal resolution, particularly with respect to the best disambiguation effect of demonstrative pronouns, provides evidence that the 3-year-old Bulgarian children understand the presented pronominal forms as deictic markers, pointing to one of the perceptually available referents.

In the next age brackets the children perceive the given antecedent sentences $\mathrm{A}, \mathrm{B}$ and $\mathrm{C}$ as highly ambiguous. Their inability to establish a clear coreference relation with the null pronoun reflects the fact that the given salience cues are not sufficient for the promotion of one referent. The presence of a highly salient and thus unambiguous referent as precondition for the use of a non-overt anaphor is given (from a Bulgarian child's perspective) only in sentence D. In sentence D the investigated salience factors endorse the same referent - the animate subject - and at the same time downgrade the second referent - the inanimate object. The double animacy/grammatical role cline is the background against which the children are able to establish a salience contrast and thus to sanction an appropriate referent for the investigated minimally complex anaphors. When children decide on the animate subject as the most salient antecedent, they start to acquire the appropriate distribution of anaphoric pronouns both in terms of production and comprehension. Within the system of anaphoric expressions in Bulgarian, this process translates to higher production rates of personal and null pronouns and to decreased rates of demonstratives. The pattern of anaphora interpretation is based on the co-reference establishment between personal pronouns and animate subjects in contexts of cue alignment. The adultlike understanding of utterances with subject-drop develops afterwards. 
At this point we want to underline that the discussed comprehension pattern of null pronouns applies to highly ambiguous contexts which are unusual in every day communication. Ultimately, the resolution behaviour of the young Bulgarian children exhibits the expected compliance with the principle of reversed mapping between complexity of anaphoric expressions and salience of referents. Bearing in mind that none of the given referents appears to be very salient according to the criteria currently applied by the child, the use of the nonovert pronouns is not appropriate. The use of the personal pronoun as a more complex form appears to be a more suitable anaphoric counterpart for a referent whose activation status is not backed by salience factors of the usual amount and strength.

\section{References}

Andrejčin, L. (1978). Osnovna bălgarska gramatika. Sofia: Nauka i izkustvo.

Ariel, M. (2001). Accessibility theory: An overview. In: T. J. Sanders, T. J. Schilperoord \& W. Spooren (eds.): Text representation: Linguistic and psycholinguistic aspects. Amsterdam: John Benjamins Publishing Company, 29-87.

Ariel, M. (2004). Accessibility marking: Discourse functions, discourse profiles, and processing cues. Discourse processes 37 (2), 91-116.

Bittner, D. (2007). Influence of animacy and grammatical role on production and comprehension of intersentential pronouns in German L1-acquisition. This volume

Bojadzhiev, T., I. Kucarov \& J. Penchev (1999). Săvremenen bălgarski ezik. Sofia: Indatelstvo "Petăr Beron".

Charalosova, K. (1995). Pokazatlnite mestoimenija v săvremennija bălgraski knizhoven ezik. In: V. Stankov (ed.): Problemi na gramatichnata sistema na bălgarskija ezik. Sofia: Akademichno izdatelstvo "Marin Drinov", 179-221.

Comrie, B. (1989). Language universals and linguistic typology. Chicago: University Press.

Gagarina, N. (2007): The hare hug the rabbit. He is white... Who is white? Pronominal anaphora in Russian. This volume

Ginina, S. (1980). Anafora, pokasatelno mestoimenie i opredelenost na imenata v bălgarskija i sărbohărvatskija ezik. Săpostavitelno ezikoznanie 5 (4): 24-32.

Givón, T. (1983). Topic continuity in discourse: A quantitative cross-language study. Amsterdam: John Benjamins Publishing Company.

Grosz, B., A. Joshi \& S. Weinstein (1995). Centering: A framework for modeling the local coherence of discourse. Computational Linguistics, 21 (2): 203-226.

Grüning, A. \& A. Kibrik (2005). Modelling Referential Choice in Discourse: A Cognitive and Calculative Approach and a Neural Network approach. In: A. Branco, T. McEnery \& R. Mitkov (eds.): Anaphora Processing: linguistic, cognitive and computational modelling. Amsterdam: John Benjamins Publishing Company, 163-198.

Gundel, J., N. Hedberg \& R. Zacharski (1993). Cognitive status and the form of referring Expressions in Discourse. Language, 69: 274-307.

Haijcova, E., B. Partee \& P. Sgall (1993). Topic-Focus Articulation, Tripartite Structure and Semantic Content. Dordrech: Kluwer Academic Publishers.

Ilieva, K. (1985). Mestoimenija i tekst. Sofia: Izdatelstvo na bălgarskata akademija na naukite. 


\section{Milena Kuehnast}

Ivančev, S (1978). Prinosi v bălgarskoto i slavjanskoto ezikoznanie. Sofia: Nauka i izkustvo.

Kaiser, E. (2005). Different forms have different referential properties: Implications for the notion of 'salience'. In: A. Branco, T. McEnery \& R. Mitkov (eds.): Anaphora Processing: linguistic, cognitive and computational modelling. Amsterdam: John Benjamins Publishing House, 261-282.

Kostadinova, P. (1995). Odushevenostta v săvremennija bălgraski knizhoven ezik. In: V. Stankov (ed.): Problemi na gramatichnata sistema na bălgarskija ezik. Sofia: Akademichno izdatelstvo "Marin Drinov", 51-85.

Kuehnast, M., Bittner, D., Gagarina, N. \& I. Gülzow (2007). Acquisition of anaphoric pronouns by German, Russian and Bulgarian speaking children. In: A. Branco, T. McEnery, R. Mitkov \& F. Silva (eds.): Proceedings of the $6^{\text {th }}$ Discourse Anaphora and Anaphor Resolution Colloquium (DAARC 2007). Porto: Centro de Linguistica da Universidade to Porto, 65-70.

Leafgren, J. (2002). Degrees of Explicitness. Information structure and the packaging of Bulgarian subjects and objects. Amsterdam: John Benjamins Publishing Company.

Levinson, S. C. (2000). Presumptive Meanings. The theory of generalized conversational Implicature. Cambridge, MA., London: MIT Press.

Mandler, J. M. (1992). How to build a baby: II. Conceptual primitives. Psychological Review, 99 (4): 587-604.

Maslov, J. S. (1981). Grammatika bolgarskogo jazyka. Moskva: "Vysshaja shkola".

Mitkov, R. (1994). An integrated model for anaphora resolution. Proceedings of the $15^{\text {th }} \mathrm{In}$ ternational Conference on Computational Linguistics (COLING'94), Kyoto, Japan.

Nicolova, R. (1986). Bălgarskite mestoimenija. Sofia: Nauka i izkustvo.

Rå Hauge, K. (1999). A Short Grammar of Contemporary Bulgarian. Bloomington:Slavica.

Sgall, P., E. Hajicova \& J. Panevova (1986). The Meaning of the Sentence and its Semantic and Pragmatic Aspects. Dordrecht: Reidel.

Strube, M. \& U. Hahn (1999). Functional Centering. Computational Linguistics, 25 (3): 309344.

Uhlirova, L. (1990). Za anaforata v bălgarskija ezik v sravnenie s cheshkija ezik. Săpostavitelno ezikiznanie, 15 (4-5):278-285. 